\title{
Mycobacterium tuberculosis Metabolism
}

\author{
Digby F. Warner \\ Medical Research Council/National Health Laboratory Services/University of Cape Town Molecular \\ Mycobacteriology Research Unit and Department of Science and Technology/National Research Foundation \\ Centre of Excellence for Biomedical TB Research, Institute of Infectious Disease and Molecular Medicine \\ and Division of Medical Microbiology, University of Cape Town, Rondebosch 7700, South Africa \\ Correspondence: digby.warner@uct.ac.za
}

Metabolism underpins the physiology and pathogenesis of Mycobacterium tuberculosis. However, although experimental mycobacteriology has provided key insights into the metabolic pathways that are essential for survival and pathogenesis, determining the metabolic status of bacilli during different stages of infection and in different cellular compartments remains challenging. Recent advances_-in particular, the development of systems biology tools such as metabolomics - have enabled key insights into the biochemical state of M. tuberculosis in experimental models of infection. In addition, their use to elucidate mechanisms of action of new and existing antituberculosis drugs is critical for the development of improved interventions to counter tuberculosis. This review provides a broad summary of mycobacterial metabolism, highlighting the adaptation of $M$. tuberculosis as specialist human pathogen, and discusses recent insights into the strategies used by the host and infecting bacillus to influence the outcomes of the host-pathogen interaction through modulation of metabolic functions.

Ultimately, the process of pathogenicity itself will be describable in terms of the chemistry of the mycobacterial cell.

—Wheeler and Ratledge (1994)

The he term "metabolism" has a very wide purview. For bacteria, it is commonly used to describe the full set of complex and interconnected chemical transformations that enable individual cells to survive and replicate. In turn, these might be broadly divided into the anabolic pathways that consume energy in generating biomass and the energy-releasing catabolic reactions that channel organic building blocks into diverse cellular structures and pathways. Metabolism also includes pathways that are es- sential to the ability of bacteria to respond to dynamic environments and to maintain structural integrity in the face of fluctuating nutrient availability. Therefore, in an obligate pathogen such as Mycobacterium tuberculosis whose entire life cycle is driven in the context of human infection, metabolism necessarily underpins both physiology and pathogenesis (Rhee 2013).

Owing to this dual role, the metabolism of M. tuberculosis has been the subject of intense research (Munoz-Elias and McKinney 2006; Beste and McFadden 2010). However, although experimental mycobacteriology_in particular, the use of genetic tools to disrupt enzymatic and regulatory functions-has provided critical insights into the metabolic pathways that are es-

Editors: Stefan H.E. Kaufmann, Eric J. Rubin, and Alimuddin Zumla

Additional Perspectives on Tuberculosis available at www.perspectivesinmedicine.org

Copyright (C) 2015 Cold Spring Harbor Laboratory Press; all rights reserved; doi: 10.1101/cshperspect.a021121

Cite this article as Cold Spring Harb Perspect Med 2015;5:a021121 


\section{D.F. Warner}

sential for mycobacterial survival and pathogenesis, it remains extremely challenging to determine the precise metabolic status of bacilli during different stages of the infection cycle in vivo and, moreover, to elucidate the extent of heterogeneity in infecting populations located in discrete cellular (micro)environments in a single infected host. For the most part, investigations of mycobacterial metabolism have concentrated primarily on elucidating the metabolic capacity of the bacillus in vitro in defined growth media and under specific environmental conditions-or in experimental models of infection-rather than investigating metabolic function directly, and at the level of the complete biological system, during tuberculosis (TB) disease (Beste and McFadden 2010; Rhee et al. 2011). This is a subtle distinction, but it has significant ramifications for any attempts to catalog bacillary metabolic status and function during different disease stages (Barry et al. 2009) and, consequently, for down- stream efforts to develop improved interventions to counter this pathogen, whether through novel antimycobacterial drugs (Lechartier et al. 2014), host-directed therapies (Schwegmann and Brombacher 2008; Hawn et al. 2013), or vaccines (Ernst 2012) (Fig. 1). Fortunately, recent developments-particularly the application of systems biology tools such as analysis of labeled metabolic intermediates (Marrero et al. 2010; Beste et al. 2011, 2013; Watanabe et al. 2011; Lee et al. 2013) in combination with major advances in mass spectrometery-based technologies (du Preez and Loots 2013; Rhee 2013; Loots 2014) - promise unprecedented access to the biochemical state of $M$. tuberculosis in experimental models of infection, as well as in determining the mechanisms of action of new and existing anti-TB drugs.

Different aspects of mycobacterial metabolism have been extensively reviewed in a number of excellent articles, and the interested reader is referred to these for detailed analyses (see Box 1).

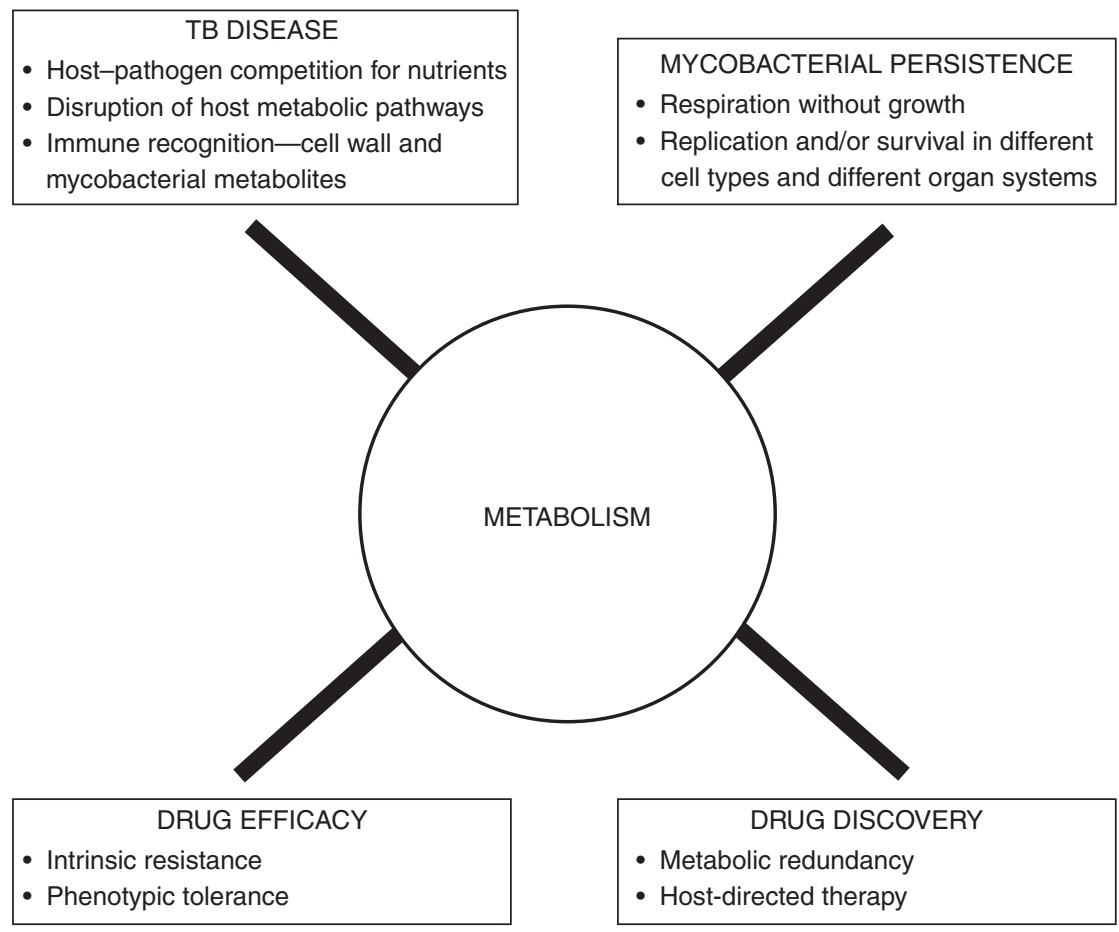

Figure 1. Metabolism impacts key features of Mycobacterium tuberculosis pathogenesis and tuberculosis (TB) disease, as well as drug efficacy and new TB drug development. 
Mycobacterium tuberculosis Metabolism

\section{BOX 1. RECOMMENDED RESOURCES}

\section{Physiology of Mycobacterium tuberculosis}

- Cook GM, Berney M, Gebhard S, Heinemann M, Cox RA, Danilchanka O, Niederweis M. 2009. Physiology of mycobacteria. Adv Microb Physiol 55: $81-319$.

- Russell DG. 2013. The evolutionary pressures that have molded Mycobacterium tuberculosis into an infectious adjuvant. Curr Opin Microbiol 16: 78-84.

\section{Central Carbon Metabolism}

- Ehrt S, Rhee K. 2013. Mycobacterium tuberculosis metabolism and host interaction: Mysteries and paradoxes. Curr Top Microbiol Immunol 374: 163-188.

\section{Cofactor Metabolism}

- Bi J, Wang H, Xie J. 2011. Comparative genomics of NAD(P) biosynthesis and novel antibiotic drug targets. J Cell Physiol 226: 331-334.

- Salaemae W, Azhar A, Booker GW, Polyak SW. 2011. Biotin biosynthesis in Mycobacterium tuberculosis: Physiology, biochemistry and molecular intervention. Protein Cell 2: 691 -695.

\section{Redox Homeostasis and Signal Transduction}

- Kumar A, Farhana A, Guidry L, Saini V, Hondalus M, Steyn AJ. 2011. Redox homeostasis in mycobacteria: The key to tuberculosis control? Expert Rev Mol Med 13: e39.

- Bretl DJ, Demetriadou C, Zahrt TC. 2011. Adaptation to environmental stimuli within the host: Two-component signal transduction systems of Mycobacterium tuberculosis. Microbiol Mol Biol Rev 75: 566-582.

\section{Sulfur, Nitrogen, and Phosphorus Metabolism}

- Hatzios SK, Bertozzi CR. 2011. The regulation of sulfur metabolism in Mycobacterium tuberculosis. PLoS Pathog 7: el002036.

- Amon J, Titgemeyer F, Burkovski A. 2009. A genomic view on nitrogen metabolism and nitrogen control in mycobacteria. J Mol Microbiol Biotechnol 17: 20-29.

- Niederweis M. 2008. Nutrient acquisition by mycobacteria. Microbiology 154: 679-692.

\section{Metallobiology}

- Rowland JL, Niederweis M. 2012. Resistance mechanisms of Mycobacterium tuberculosis against phagosomal copper overload. Tuberculosis (Edinb) 92: 202-210.

- Riccardi G, Milano A, Pasca MR, Nies DH. 2008. Genomic analysis of zinc homeostasis in Mycobacterium tuberculosis. FEMS Microbiol Lett 287: 1 -7.

\section{Enzymology}

- Hudson SA, McLean KJ, Munro AW, Abell C. 2012. Mycobacterium tuberculosis cytochrome P450 enzymes: A cohort of novel TB drug targets. Biochem Soc Trans 40: 573-579.

- Selengut JD, Haft DH. 2010. Unexpected abundance of coenzyme F420-dependent enzymes in Mycobacterium tuberculosis and other actinobacteria. J Bacteriol 192: 5788-5798. 


\section{D.F. Warner}

In addition, literature in this subject collection focused on specific areas of $M$. tuberculosis physiology and metabolism, including the factors influencing mycobacterial growth (Uhía et al. 2014) and cell wall composition and homeostasis (Alderwick et al. 2014; Jackson 2014). Therefore, this review will provide a broad overview of metabolism in M. tuberculosis, focusing primarily on the pathways involved in central carbon metabolism and highlighting recent findings implicating specific metabolic functions in mycobacterial pathogenesis. It will also consider the increasing impact of "omics" technologies in elucidating the metabolic state of bacilli in different models of infection, with special reference to the influence of mycobacterial metabolism on the host-pathogen interaction. As noted previously (Warner and Mizrahi 2008), investigations of core metabolic processes in M. tuberculosis are generally aimed (explicitly or implicitly) at identifying essential functions and potential vulnerabilities that might be targeted in novel intervention strategies; therefore, the discussion throughout will be framed within the context of new TB drug discovery, with an emphasis on recent insights into the influence of bacillary metabolic status on antibiotic efficacy, as well as in the application of advanced analytic tools to determine antibiotic mechanisms of action.

\section{MYCOBACTERIAL METABOLISM AND HUMAN TB DISEASE}

M. tuberculosis is transmitted in infectious aerosols, which are inhaled deep into the lung alveoli where the bacilli lodge in terminal air spaces and are engulfed by resident alveolar macrophages and recruited neutrophils (O'Garra et al. 2013). A hallmark of pathogenic mycobacteria is the ability to block normal acidification of phagosomes by preventing phagolysosmal fusion, enabling infecting bacilli to establish an intracellular niche that is conducive for replication in inactivated macrophages that offer limited antimicrobial defense (Russell 2011). There, the bacilli undergo several rounds of replication; however, following recruitment of innate immune components, host effectors such as reac- tive oxygen and nitrogen intermediates are released and mycobacterial replication slows. Immune activation results in the recruitment of lymphocytes and additional macrophages that assemble into a granuloma, a multicellular structure that sequesters the infecting bacteria from the surrounding tissue, and further inhibits the bacillary replication rate. Ultimately, the interior of the granuloma becomes necrotic (or "caseous") and hypoxic (Via et al. 2008), and bacilli are thought to enter a quiescent state characterized by limited or no replication and phenotypic resistance to drugs targeting processes such as cell wall biosynthesis (Karakousis et al. 2008). Evidence from various experimental systems, including macrophage (Rohde et al. 2012), mouse (Gill et al. 2009), and nonhuman primate (Lin et al. 2013) models, is consistent with the idea that, following infection, bacilli undergo several rounds of rapid replication, after which the increase in total bacterial number slows dramatically as a consequence of host-mediated killing and ultimately declines. Moreover, by applying a "clock plasmid" through both acute and chronic phases, it has been shown that replication continues throughout infection in the mouse model (Gill et al. 2009), an observation which appears to be supported in nonhuman primates as well in the emergence of chromosomal mutations during latent infection (Ford et al. 2011). In turn, this suggests that bacillary numbers are maintained at suppressed levels during long-term infection owing to active immune surveillance and killing.

M. tuberculosis is not restricted to specific host cellular compartments during infection (Dartois and Barry 2013; Dartois 2014). In cellular granulomas, bacilli are located predominantly within macrophages as well as in some extracellular niches; in caseous centers of necrotic granulomas, they are extracellular and considered metabolically quiescent (O'Garra et al. 2013). Bacilli are also found on the inner surface of open cavities within multiple cell types and even extracellular (Eum et al. 2010; Lowe et al. 2012), where they are protected from the immune system and able to replicate freely (Kaplan et al. 2003). In addition, there is 
molecular evidence that bacilli are located in a variety of cells in distal loci of the lung-despite the absence of any clear histological evidence of infection (Hernandez-Pando et al. 2000) -as well as in other organs (Barrios-Payan et al. 2012). The occupation of discrete tissues and cell types implies that individual bacteria from a clonal infecting population might be characterized by different physiological (and, in turn, metabolic) states, even where located within the same microenvironment-perhaps by analogy with the significant heterogeneity in host cell type and function within organized granulomas (Mattila et al. 2013).

From the perspective of mycobacterial metabolism, the bacilli are predicted to access glucose and triacylglycerides as primary carbon sources during early replication under aerobic conditions; thereafter the glucose-deficient macrophage environment forces a shift to the utilization of lipids (Boshoff and Barry 2005). As the infection proceeds, and there is increased immune activation and host-imposed stress, normal aerobic respiration becomes increasingly limited and the bacterium switches metabolism to ensure maintenance of an energized membrane in the absence of growth (Watanabe et al. 2011; Eoh and Rhee 2013). It is simplistic, therefore, to assume that mycobacterial metabolism has been selected to generate maximal bacillary numbers within a given microenvironment. The identification of immunopathology (imp/pat) mutants impaired in their ability to cause characteristic disease pathology despite showing no growth defect reinforces the important disconnect between bacillary number and disease outcome (Hingley-Wilson et al. 2003). Similarly, the idea that metabolic activity is designed to maximize mycobacterial biomass and energy production from limited nutrient sources is problematic (Rhee et al. 2011). M. tuberculosis does not have to outcompete other organisms within the same niche. Moreover, the pathology characteristic of TB disease is not mediated by bacterial toxins but instead reflects the host immune response to mycobacterial antigens (Ernst 2012).

Recent evidence from the nonhuman primate model indicates that the bacterial pop- ulation within individual pulmonary lesions achieves a maximum size that is fairly consistent, numbering approximately $2 \times 10^{5}$ bacilli per lesion just before the onset of the adaptive immune response and stabilizing at a median of approximately $10^{2}$ bacilli during active disease (Lin et al. 2013). It is only those permissive lesions that exceed the characteristic "carrying capacity" that spread locally or result in TB pneumonia (Lin et al. 2009). It seems likely, therefore, that maximal growth might be detrimental to the immediate fate of the infecting bacillus (individual host outcome) or to its long-term survival (evolutionary persistence within the human population). The phenotypes of hypervirulent mutants, for example, often result from mutations in structural and regulatory genes (Parish et al. 2003; Shimono et al. 2003; Hu et al. 2006), perhaps indicating that M. tuberculosis virulence is tightly controlled. As discussed below, however, the extent to which metabolic activity varies in different host tissues and within specific cell types remains unresolved, as does the manner in which host cell activation impacts bacillary metabolic state.

\section{Cataloging Mycobacterial Metabolic Capacity}

If the genetic repertoire of a pathogen can be used to infer key characteristics of its lifestyle, the M. tuberculosis genome suggested an organism equipped with metabolic flexibility and autonomy, as well as the inherent capacity to resist nutrient stress (Cole et al. 1998). M. tuberculosis is a prototroph, possessing the biosynthetic capacity for amino acids, vitamins, and cofactors. In addition to a massively expanded complement of genes involved in fatty acid metabolism, the mycobacterial genome encodes a functional tricarboxylic acid cycle, pentose phosphate and Embden-Meyerhof-Parnas pathways, as well as enzymes offering a metabolic link between glycolytic and tricarboxylic acid pathways, suggesting the ability to switch between sugars, host-derived fatty acids, glucose, tricarboxylic acids, amino acids, and cholesterol as sources of nitrogen, carbon, and energy during host infection. Consistent with early predictions, phe- 


\section{D.F. Warner}

notypic and transcriptional analyses of bacilli grown under defined conditions in vitro, or harvested from clinical infections, reinforced the inferred dependence of M. tuberculosis on fatty acids as primary carbon source (Schnappinger et al. 2003; Timm et al. 2003; Rohde et al. 2012). These observations have been reinforced and refined in a large number of studies (McKinney et al. 2000; Pandey and Sassetti 2008; de Carvalho et al. 2010a; Marrero et al. 2010; Rhee et al. 2011; Lee et al. 2013), which have applied targeted gene-deletion and knockdown mutants, in some cases in combination with metabolomic approaches, in a variety of experimental models in vitro and in vivo to arrive at a common conclusion: $M$. tuberculosis uses fatty acids as its predominant source of carbon and energy during host infection (discussed below).

Central carbon metabolism intersects with pathways involved in maintaining nitrogen homeostasis at $\alpha$-ketoglutarate, a substrate of the key tricarboxylic acid cycle enzyme, $\alpha$-ketoglutarate dehydrogenase, as well as glutamate synthase. Competition for $\alpha$-ketoglutarate is therefore subject to complex regulation to ensure efficient partitioning between energy generation and anabolism. Recent evidence in $M$. tuberculosis implicates GarA, a forkhead-associated (FHA) domain-containing protein, of controlling the activities of three enzymes that use $\alpha$-ketoglutarate-inhibiting $\alpha$-ketoglutarate dehydrogenase, activating glutamate synthase, and inhibiting glutamate dehydrogenase (Ventura et al. 2013). Because GarA is itself subject to phosphorylation and binds multiple kinases (Molle and Kremer 2010), this observation points to the critical, but largely unexplored, role of posttranslational modifications in regulating core metabolic processes in $M$. tuberculosis.

\section{Recent Insights into Carbon Metabolism}

The observed attenuation of mutants defective in gluconeogenesis, the glyoxylate cycle, and the methylcitrate cycle (McKinney et al. 2000; Munoz-Elias and McKinney 2005; Munoz-Elias et al. 2006; Marrero et al. 2013) supports the inferred importance of carbon metabolism for mycobacterial pathogenesis. Moreover, a series of studies have elucidated the functional plasticity inherent in the mycobacterial tricarboxlic acid cycle, in turn implying the ability to use a variety of substrates under different oxygen tensions and in nutritionally diverse host environments (Tian et al. 2005a,b; Baughn et al. 2009; Wagner et al. 2011; Watanabe et al. 2011). Recent analyses using ${ }^{13} \mathrm{C}$-metabolic flux analysis suggest an additional, anabolic role for isocitrate lyase in a so-called "GAS pathway," in which pyruvate dissimilation is achieved at slow growth rates and in glycerol-limited conditions via the glyoxylate shunt and carboxylating anaplerotic reactions (involving phosphoenolpyruvate carboxykinase, pyruvate carboxylase, and malic enzyme), which enable fixation of exogenous $\mathrm{CO}_{2}$ and generation of biomass via succinyl CoA (Beste et al. 2011). The ability to derive carbon from $\mathrm{CO}_{2}$ was confirmed in follow-up studies from the same group in an experimental model that also suggested the ability of $M$. tuberculosis to assimilate amino acids including alanine, glutamate/glutamine, and asparagine/aspartate from the host macrophage (Beste et al. 2013). Importantly, these observations are consistent with prior in vitro results that established the ability of M. tuberculosis to cocatabolize multiple carbon sources simultaneously via compartmentalization of discrete metabolic processes (de Carvalho et al. 2010a). The capacity for differential catabolism through glycolytic, pentose phosphate, and/or tricarboxylic acid pathways suggests that in vitro growth media should be adjusted to ensure physiologically relevant metabolic activity, particularly in drug screens (discussed below). However, further research is required to determine the relative contribution of different metabolic functions to $M$. tuberculosis during different growth stages and in different cellular locations. In addition, recent evidence implicating the LpqY-SugA-SugB-SugC ATP-binding cassette transporter in the critical recycling of trehalose (Kalscheuer et al. 2010) raises questions about the potential role of carbohydrates in mycobacterial metabolism in vivo (Rhee et al. 2011). 
Mycobacterium tuberculosis Metabolism

The consumption of alternative carbon sources including odd- and branched-chain fatty acids, branched-chain amino acids, and cholesterol generates propionyl CoA as a three-carbon terminal product. This poses a problem for M. tuberculosis in terms of its ability to balance the relative intracellular levels of two- and threecarbon intermediates-propionate is a highenergy metabolite but is toxic to $M$. tuberculosis if accumulated in elevated concentrations. $M$. tuberculosis possesses two major pathways for propionate catabolism - the methylcitrate cycle, which depends on the function of isocitrate lyase (Munoz-Elias et al. 2006), and the methylmalonyl pathway, which uses a vitamin $\mathrm{B}_{12}$ dependent methylmalonyl CoA mutase (Savvi et al. 2008). Consistent with the inferred importance of propionate metabolism for M. tuberculosis pathogenesis, previous evidence suggested that, during in vivo infection in a mouse model, bacilli synthesized high-mass phthiocerol dimycocerosate (PDIM) forms via methylmalonylCoA derived from the $\beta$-oxidation of host lipids (Jain et al. 2007). More recently, however, it has been shown that, in addition to these two pathways, M. tuberculosis is able to limit propionylCoA accumulation by shunting excess subunits into the methyl-branched virulence lipids, sulfolipid-1 and PDIM, which act as a "sink" (Lee et al. 2013). Moreover, by labeling macrophage lipid droplets with ${ }^{14} \mathrm{C}$-propionate, ${ }^{14} \mathrm{C}$-oleate, and ${ }^{14} \mathrm{C}$-stearate before infection, the investigators showed that M. tuberculosis incorporates host-derived lipids into PDIM, thereby confirming the ability of intracellular bacilli to access host fatty acid stores. In addition to reinforcing the close metabolic interaction between infecting pathogen and its cellular environment, these observations suggest that fluctuations in the amount of propionate routed into cell wall lipids will affect the host-pathogen interaction. Furthermore, because the methylmalonyl pathway depends on vitamin $\mathrm{B}_{12}$ for activity, the availability of this cofactor is likely to determine relative flux through the different routes (Griffin et al. 2012). In turn, this observation reinforces the potential impact of metabolic activity on disease progression and pathology and highlights the importance of determining the levels of key metabolites and cofactors in different host compartments.

\section{Metabolism in the Absence of Growth}

A seminal review (Boshoff and Barry 2005) pointed out that even nonreplicating bacilli must retain sufficient basal metabolic activity to ensure maintenance of an energized cell membrane as well as core cellular processes. Of particular importance is the need to sustain lowlevel ATP production and the continual regeneration of reducing equivalents in the form of $\mathrm{NAD}^{+}$to maintain the proton motive force. The first of two key studies investigating this notion used metabolomics and isotopomer analyses to investigate the shift in central metabolism in $M$. tuberculosis during replication arrest under diminishing oxygen conditions (Watanabe et al. 2011). The results confirmed a significant decrease in intracellular ATP levels in oxygen-starved bacilli relative to active aerobic growth and a large increase in the ratio of $\mathrm{NADH}$ to $\mathrm{NAD}^{+}$. To alleviate this effect, bacilli grown on glucose initiate a reversed TCA cycle, which results in the net incorporation of $\mathrm{CO}_{2}$ and the active secretion of succinate in a fermentative respiratory strategy. The critical role of succinate in hypoxic adaptation in M. tuberculosis was reinforced in separate work that also measured intermediates of the mycobacterial TCA cycle during the shift to anoxia, although in this case acetate was supplied as primary carbon source so as to mimic the inferred importance of fatty acid metabolism for mycobacterial pathogenesis (Eoh and Rhee 2013). The results implicated the glyoxylate shunt in the generation of succinate and glycine, specifically identifying functional isocitrate lyase as critical to this process, and thereby establishing an additional role for the enzyme independent from its established contribution to fatty acid catabolism (Munoz-Elias and McKinney 2005). Based on these observations, the investigators proposed that succinate functions as a "metabolic battery" in M. tuberculosis, ensuring sustained membrane potential, ATP synthesis, and supply of TCA cycle intermediates. Although this suggests key components of the fermentative pro- 
D.F. Warner

cess as potential drug targets for latent $\mathrm{TB}$, it also prompts an important question about the impact of secreted succinate on the local inflammatory response. Recent evidence implicating macrophage-derived succinate in innate immune signaling (Tannahill et al. 2013) raises the possibility that mycobacterial metabolic shutdown might be coupled with decreased host immune activity.

\section{MYCOBACTERIAL METABOLISM AND THE HOST IMMUNE RESPONSE}

M. tuberculosis has adapted to human infection over 70,000 years of coevolution (Comas et al. 2013). Any analysis of metabolic function in this bacterium must, therefore, consider the influence of metabolism on the host-pathogen interaction. Because infecting bacilli are wholly dependent on their human host for increased biomass, access to nutrients represents a critical point of conflict. For this reason, mechanisms directly regulating nutrient and trace metal availability are key to an effective host immune response and involve both starving (Wagner et al. 2005; Zhang et al. 2013b) or poisoning (Botella et al. 2011) the infecting bacilli, which themselves use countermeasures such as the mobilization of specific small molecule effectors including cAMP to modulate host immune function (Agarwal et al. 2009). Infection with M. tuberculosis can also impact cellular metabolism; for example, by diverting glycolysis toward ketone body biosynthesis, $M$. tuberculosis actively disrupts macrophage metabolic homeostasis to promote the accumulation of lipid bodies (Singh et al. 2012). This process, which is mediated by mycobacterial mycolic acids and ensures the incorporation of phagosomal bacilli into intracellular lipid bodies, induces a nonreplicating state in $M$. tuberculosis, suggesting that the resultant foamy macrophages constitute an important reservoir of persistent organisms (Peyron et al. 2008). Similarly, transcriptional and biochemical analyses are consistent with the idea that $M$. tuberculosis infection dysregulates host lipid metabolism so that the caseating granulomas characteristic of active TB disease comprise the preferred carbon sources of the bacillus-cholesterol, triacylglycerides, and glycosphingolipids (Kim et al. 2010).

It has been proposed, too, that M. tuberculosis causes a nutritional imbalance that triggers autophagy in infected macrophages (Kumar and Rao 2011). In support of these observations, pioneering RNAi screens to elucidate host factors that are critical to controlling intracellular infection identified genes involved in metabolic regulation and function (Jayaswal et al. 2010; Kumar et al. 2010). More recently, immunoresponsive gene 1 ( $\operatorname{rg} 1$ ) has been implicated in the inhibition of $M$. tuberculosis through the production of itaconic acid (Michelucci et al. 2013), a succinate analog that inhibits isocitrate lyase and is induced in activated macrophages (Strelko et al. 2011). Itaconate has been usefully applied in vitro to show the existence of a functional citramalate cycle in some bacteria (Berg et al. 2002); therefore, the detection of elevated citramalate concentrations in sputum samples from patients with active TB disease (du Preez and Loots 2013) is intriguing, particularly given the inferred importance of succinate in host immune function (Tannahill et al. 2013).

Emerging evidence from different bacterial systems, as well as M. tuberculosis, reinforces the notion that metabolism is fundamental to host-pathogen dynamics. For example, Group A Streptococcus directly modulates asparagine production by host cells, in turn triggering expression of an asparagine-responsive gene regulon that stimulates bacterial proliferation ( $\mathrm{Ba}-$ ruch et al. 2014). Critically, this study showed that degradation of asparagine through the administration of asparaginase resulted in bacterial growth arrest, thereby suggesting a novel antibacterial intervention targeting host amino acid homeostasis. Recent work by Eric Rubin and colleagues has similarly situated tryptophan homeostasis at the nexus of the mycobacterium-host interaction (Zhang et al. 2013b). Using a transposon insertion site-mapping method pioneered in the same laboratory (Sassetti and Rubin 2003), the investigators identified the set of mycobacterial genes that is essential to the ability of the bacillus to survive in an immune-competent host (Zhang et al. 2013b). 
Consistent with previous observations, these included genes required for gluconeogenesis, reinforcing the inferred role of fatty acid catabolism in M. tuberculosis pathogenesis (Marrero et al. 2010). In addition, the analysis of underrepresented genes revealed a specific requirement for a functional tryptophan biosynthetic pathway. Immune activation triggers up-regulation of host indoleamine 2,3-dioxygenase, an enzyme involved in tryptophan catabolism, as part of an established antimicrobial response that effectively starves invading pathogens of the essential amino acid. Like some other bacteria, M. tuberculosis counters this mechanism by synthesizing tryptophan de novo, thereby identifying the tryptophan biosynthetic machinery as a potential therapeutic target. Using fluorinated anthranilate derivatives, the investigators showed that inhibition of the essential anthranilate synthase, TrpE, was bactericidal in vitro and limited growth in the mouse model (Zhang et al. 2013b).

Microbial metabolites are antigens for host immune detection; for example, vitamin $\mathrm{B}_{2}$ and vitamin $\mathrm{B}_{9}$ derivatives are natural ligands for the MHC class I-like related molecule (MR1) on mucosal-associated invariant T (MAIT) cells (Kjer-Nielsen et al. 2012), and they can also modulate host immune function (Smith et al. 2013). In turn, this implies that tight spatial and temporal control of metabolism is likely to be critical to an obligate pathogen whose entire life cycle occurs within the context of host infection and, therefore, immune surveillance. Indirect support of this idea is provided by the observation that metabolic enzymes are among the confirmed T-cell epitopes that appear to be hyperconserved (Comas et al. 2010), suggesting that the gene products as well as their metabolic functions are under direct negative selectionfor example, glutamine synthetase, a secreted enzyme which is thought to be involved in bacillary regulation of host intracellular $\mathrm{pH}$ through disrupted ammonia metabolism (Kumar and Rao 2011). In contrast, comparative genomics suggests that various metabolic functions have been gained or lost during the evolution of modern M. tuberculosis strains from the ancestral smooth tubercle bacillus (Stinear et al. 2008; McGuire et al. 2012; Supply et al. 2013), including those required for the biosynthesis of cofactors such as molybdopterin (Williams et al. 2014) and vitamin $\mathrm{B}_{12}$ (Gopinath et al. 2013a). Similarly, inactivating polymorphisms and large deletions affecting genes involved in intermediary metabolism are overrepresented in comparative genomic analyses of circulating clinical isolates, suggesting strong selection pressure on specific metabolic functions (Tsolaki et al. 2004; Warner et al. 2007). The extent to which the loss of these genes impacts the short-term competitive survival and, on a longer timescale, the persistence of the evolved mutant within the human population is unclear and requires further investigation.

\section{INVESTIGATING MYCOBACTERIAL METABOLISM IN VIVO}

\section{Auxotrophs as Bioprobes of Host Environments}

There has been considerable activity around the construction of amino acid auxotrophs (Hinshelwood and Stoker 1992; McAdam et al. 1995; Gordhan et al. 2002; Parish 2003), mainly for their possible development as live-attenuated vaccines (Chambers et al. 2000; Smith et al. 2001; Pavelka et al. 2003; Sampson et al. 2004, 2011). In different mouse models, arginine (Gordhan et al. 2002), lysine (Pavelka et al. 2003), leucine (McAdam et al. 1995; Chambers et al. 2000), methionine, proline, and tryptophan auxotrophs (Smith et al. 2001) are severely attenuated, suggesting the inability of the infecting mycobacteria to scavenge adequate sources of the respective essential amino acids from the host. Double-auxotrophic mutants of $M t b$ have also been constructed carrying inactivating deletions in pantothenate (vitamin $\mathrm{B}_{5}$ ) and either lysine (Sambandamurthy et al. 2005; Larsen et al. 2009) or leucine (Sampson et al. 2004, 2011) biosynthetic pathways and fail to cause disease in multiple animal models. These attenuated strains have also found practical use under biological safety II conditions-for example, in a complex high-throughput drug screen 
D.F. Warner

to identify compounds that are active against nonreplicating bacilli (Gold et al. 2012).

Notwithstanding the potential prophylactic applications, auxotrophic mutants can prove extremely useful as probes of the host environment. For example, the profound in vivo attenuation of the arginine auxotroph (Gordhan et al. 2002) is unexpected given the critical role of arginine as substrate for nitric oxide (NO) production in M. tuberculosis-infected macrophages (Qualls et al. 2012), implying the inability of the bacillus to transport specific amino acids in vivo. Alternatively, it might indicate the capacity of infected host cells to sequester specific amino acids, as described for tryptophan (Zhang et al. 2013b). As noted above, amino acids such as asparagine, glutamate, and aspartate serve as organic sources of nitrogen, which implicates amino acid transport and assimilatory mechanisms in pathogenesis independent of the corresponding biosynthetic pathways. For example, recent work has established that M. tuberculosis requires host-derived aspartate (Gouzy et al. 2013). Deletion of the aspartate transporter, AnsP1, resulted in severe growth attenuation during infection of both wild-type and immunodeficient mice and was associated with reduced pathology. In addition to identifying the aspartate transporter, this study is notable for two reasons. First, the observation that in vitro models do not necessarily reproduce key aspects of the host environment-the ansP1 mutant showed no growth defect in macrophages, in contrast to the profound phenotype observed in vivo. Second, the involvement of AnsP1 in aspartate assimilation-the MTB genome encodes paralogous AnsP1 and AnsP2 proteins that show significant identity to asparagine transporters, yet although AnsP1 is essential for aspartate uptake, followup work from the same group has implicated AnsP2 in a asparagine transport and catabolism in combination with the secreted asparaginase, AnsA (Gouzy et al. 2014). Deletion of AnsP2 does not eliminate nitrogen assimilation from asparagine, suggesting that another protein(s) compensates for loss of function. By analogy with the recent identification of the mycobacterial corrinoid (Gopinath et al. 2013b) and heme
(Tullius et al. 2011; Owens et al. 2013) transporters, this observation reinforces the need to identify the mechanisms that mediate uptake of essential nutrients, cofactors, and trace elements in M. tuberculosis and simultaneously highlights the unique adaptation of conserved proteins to specialist functions in an obligate pathogen (discussed below). In addition, the dual role of the ansA-encoded asparaginase in mycobacterial nitrogen homeostasis and the defense against host-mediated acid stress reinforces the intersection of physiology and virulence in core metabolic functions.

\section{Advances in the Postgenomic Era}

Knockout mutants, whether containing targeted or random disruptions of metabolic enzymes, are limited in their ability to provide insights into the temporal requirements for specific metabolic functions. Moreover, the use of transposon libraries to infer gene essentiality is complicated by the potential of a population of bacilli containing wild-type alleles to compensate in trans for loss of a specific function in the corresponding insertion mutant (s). Systems that allow conditional knockout (or knockdown) of target genes by promoter replacement or regulated protein degradation through the use of tetracycline-responsive genetic elements (Ehrt et al. 2005) have provided a powerful solution to this problem, enabling confirmation of inferred essentiality under a variety of conditions in vitro, as well as precise determinations of the stage of infection at which particular metabolic functions are critical for survival in vivo (Blumenthal et al. 2010; Wei et al. 2011; Kim et al. 2013). For the same reasons, conditional mutants are also very useful in validating putative drug targets (Blumenthal et al. 2010; Kolly et al. 2014), as well as in enabling assessments of the vulnerability of the mycobacterial cell to partial disruption of a specific function (Wei et al. 2011). In addition, the intrinsic resistance of M. tuberculosis to most antibiotic compounds has suggested the utility of applying conditional mutants in novel approaches such as target-based whole-cell screening (Lechartier et al. 2014); for example, a con- 
ditional knockdown of pantothenate synthase, pan $C$, was recently used to identify potential small-molecule inhibitors of the essential vitamin $B_{5}$ biosynthetic pathway (Abrahams et al. 2012).

As noted elsewhere (Beste and McFadden 2010; Rhee 2013), an inherent weakness of all genetic manipulations is that the phenotype of the resulting mutant might reflect the loss of a function(s), which cannot be predicted by genetic or bioinformatic analyses. In addition, evidence from other bacterial systems indicates that metabolic networks are robust and tolerate perturbations via compensatory and regulatory mechanisms that are often mediated at multiple levels through complex protein networks (Ishii et al. 2007). The absence of a discernible phenotype at the cellular level might, therefore, obscure the underlying metabolic adjustment necessary to maintain homeostasis. Attempts to circumvent these limitations are increasingly reliant on the so-called "metabolomics" approaches, which do not require genetic manipulation of mycobacterial gene function, but instead depend on the ability to detect, and quantify, specific molecules (metabolites) that can provide detailed information about the metabolic state of the bacillus at a specific instant (i.e., a snapshot of the biochemical makeup of the cell). By definition, the instantaneous cellular composition is a function of the regulatory and other metabolic pathways whose combined activities have yielded the observed state; for this reason, metabolomics is complementary to other approaches such as proteomics, lipidomics, and transcriptomics, and combinations of these techniques can be harnessed to generate true systems biology data (Galagan et al. 2013).

Owing to the considerable technical challenges (Boshoff and Lun 2010), metabolomics has been most profitably applied during growth of $M$. tuberculosis under defined conditions in vitro (de Carvalho et al. 2010a; Beste et al. 2011, 2013; Watanabe et al. 2011), although there is increasing use of metabolite profiling to identify biomarkers of infection in experimental models as well as clinical specimens (Shin et al. 2011; du Preez and Loots 2013; Zhou et al. 2013; Maha- patra et al. 2014). As noted above, these techniques have proved especially useful in enabling key insights into central carbon metabolism in M. tuberculosis and, in addition to investigating known pathways, have revealed cryptic biochemical functions. For example, activity-based metabolomic profiling has enabled functional annotation of conserved and hypothetical proteins such as D,L-glycerol 3-phosphate phosphatase, whose presence in the genome implies that $M$. tuberculosis has the metabolic machinery to catabolize glycerophospholipids (LarrouyMaumus et al. 2013), as well as 2-hydroxy-3-oxoadipate synthase (de Carvalho et al. 2010b). Similarly, pathway profiling established that the primary function of the igr operon is to degrade the $2^{\prime}$-propanoate side chain of cholesterol (Thomas et al. 2011).

Metabolomic analyses have also been used to identify potential biomarkers of disease. Experimental models, including mice and guinea pigs (Shin et al. 2011; Somashekar et al. 2012), have established that M. tuberculosis infection has a profound impact on host metabolism, and these observations have been reiterated in clinical samples where differential metabolite profiles have been used to distinguish uninfected controls from latently infected patients as well as those with active disease (Weiner et al. 2012b; Zhou et al. 2013). Of special interest is the identification of kynurenine as a defining metabolite of active TB (Weiner et al. 2012b), because this is the product of the indoleamine2,3-dioxygenase-catalyzed degradation of tryptophan that, as detailed above, recent work has implicated in the host antimycobacterial response (Zhang et al. 2013b). Other approaches include the analysis of sputum for both mycobacterial and host markers of disease (du Preez and Loots 2013), as well as the development of urinary metabolite signatures to track the response to chemotherapy (Mahapatra et al. 2014). In addition, differential metabolite profiles have been investigated as a method to speciate pathogenic and nonpathogenic mycobacteria (Olivier and Loots 2012) and to investigate the impact of drug resistance mutations on bacterial physiology (Bisson et al. 2012; Loots 2014), as discussed further below. 
D.F. Warner

\section{TB DRUG DISCOVERY AND M. tuberculosis METABOLISM}

\section{Targeting Mycobacterial Metabolism}

The metabolic capacity of an obligate pathogen such as M. tuberculosis is critical to drug discovery for interrelated reasons: First, it determines which metabolic pathways or functions are essential for pathogenesis, and so might represent preferred antibiotic targets; and, second, it influences predictions around the prospective efficacy of any new drug or drug combination because redundant function, or the potential for alternative metabolic pathways or states, could render a potent in vitro compound useless in disease-relevant conditions. The risk of redundant (or alternative) function is exacerbated by the fact that approximately one-quarter of the M. tuberculosis genome lacks functional annotation (Lew et al. 2013; Slayden et al. 2013). Moreover, consistent with the inferred evolution of $M$. tuberculosis as specialist pathogen from an ancestral generalist environmental Mycobacterium (Stinear et al. 2008; McGuire et al. 2012), genes annotated on the basis of close homology with orthologs in other organisms can encode proteins that have evolved completely novel and/or additional functions. Compelling examples include the recently identified aspartate (Gouzy et al. 2013) and vitamin $\mathrm{B}_{12}$ (Gopinath et al. 2013b) transporters, as well as the multiple subunits of the pyruvate dehydrogenase complex, which were almost entirely misannotated (Rhee et al. 2011) and include the dlaT-encoded dihydrolipoamide acyltransferase (Tian et al. 2005b) and $l p d$-encoded lipoamide dehydrogenase (Venugopal et al. 2011). For this reason, functional annotation of the M. tuberculosis genome remains a critical research priority (Slayden et al. 2013).

As noted above, investigations of metabolic capacity in $M$. tuberculosis have been framed largely within the context of drug discovery, with a particular focus on the identification of vital (essential) genes or pathways as potential targets. The "essential gene lists" derived in the landmark studies of Christopher Sassetti, Eric Rubin, and colleagues (Sassetti et al. 2003; Sas- setti and Rubin 2003), refined in a series of subsequent iterations exploring different infection models (Rengarajan et al. 2005; Brodin et al. 2010; Griffin et al. 2011; Zhang et al. 2013b), have been routinely applied as a starting criterion in target selection and prioritization (Warner and Mizrahi 2012). In turn, this has motivated efforts to develop in vitro growth models that more closely resemble the host environments encountered by $M$. tuberculosis (Franzblau et al. 2012; Dartois and Barry 2013). These studies have catalogued a range of carbon sources (Baek et al. 2011), pH values (Vandal et al. 2008), and oxygen tensions (Cho et al. 2007) in which the bacillus is able to survive and, in most cases, replicate, even in the presence of applied stimuli such as oxidative and nitrosative stresses (de Carvalho et al. 2011; Gold et al. 2012). In addition, alternative screens have been developed against bacilli contained within macrophages (Christophe et al. 2009; Stanley et al. 2014) or grown under conditions that are predicted to obtain during host infection (de Carvalho et al. 2009; Franzblau et al. 2012; Gold et al. 2012).

An instructive example of the direct impact of growth medium composition on drug efficacy was provided by the identification of the pyrimidine-imidazole class of compounds that, despite impressive in vitro potency against M. tuberculosis, were inactive in vivo owing to the fact that their inhibitory activity was dependent on metabolic poisoning of bacilli grown in media containing glycerol (Pethe et al. 2010). To counter this effect, most in vitro screening algorithms now use more than carbon source (Franzblau et al. 2012). Nevertheless, determining the in vivo availability of specific lipids, amino acids, cofactors, and trace metals remains critical for antibiotic discovery, as there are a number of cases in which the unexpected ability of different bacteria to scavenge essential nutrients from the host has precluded further development of very promising lead compounds as clinic candidates (Brinster et al. 2009). In addition, there is strong evidence for the impact of metabolic state on drug efficacy; for example, the bactericidal activity of bedaquiline, an ATP synthase inhibitor, is significantly enhanced 
during growth of $M$. tuberculosis on nonfermentable energy sources such as lipids, which limit the ability of the bacillus to generate ATP via glycolysis (Koul et al. 2014).

Current TB drug screening programs are characterized by significant redundancy in the nature of the compounds screened, as well as the putative targets, with mutations in a handful of "promiscuous" cell wall-associated proteins (e.g., DprE1, MmpL3, and QcrB) accounting for a large proportion of resistance phenotypes (Goldman 2013). There are, however, promising examples of the potential to inhibit other metabolic functions. These include the identification of sulfonamides and rhodanines that, respectively, target lipoamide dehydrogenase (Bryk et al. 2013) and dihydrolipoamide acyltransferase (Bryk et al. 2008), components of both the mycobacterial pyruvate dehydrogenase and peroxynitrite reductase complexes and, therefore, critical for intermediary metabolism as well as oxidative and nitrosative defense (Tian et al. 2005a; Shi and Ehrt 2006; Venugopal et al. 2011). Alternative approaches include the development of ATP-competitive inhibitors of enzymatic activities that are essential for active replication and/or hypoxia-induced nonreplication (Wolfe et al. 2013), as well as small molecules to disrupt biotin biosynthesis (Shi et al. 2011) or posttranslational biotinylation that is essential for protein function (Duckworth et al. 2011).

\section{Mycobacterial Metabolism and Drug Efficacy}

Altering key environmental variables can impact the mycobacterial growth rate, triggering a shift to an alternative metabolic state (Beste et al. 2005) that, in turn, can impact susceptibility to specific drugs. For example, growth arrest owing to a variety of stresses thought to prevail during host infection, including hypoxia, iron limitation, and low $\mathrm{pH}$, has been associated with a metabolic shift in M. tuberculosis that directs carbon away from the TCA cycle and into the biosynthesis of triacyglycerol, which accumulates in the cytosol (Baek et al. 2011). The resulting metabolic shutdown renders
M. tuberculosis tolerant to a number of antibiotics and so suggests a direct link between bacterial metabolic state and observed drug efficacy. This effect is reproduced during intracellular infection as well; under hypoxic conditions, M. tuberculosis-infected macrophages accumulate lipid droplets, which the bacilli import and assimilate into their own triacylglycerol stores (Daniel et al. 2011). Consistent with in vitro observations (Baek et al. 2011), the ability to use host-derived lipids is dependent on functional triacylglycerol synthase, Tgs1 (Daniel et al. 2011). Moreover, sputum samples from TB patients contain a subpopulation of nonreplicating bacilli loaded with triacylglycerol lipid bodies (Garton et al. 2008), raising the possibility that this state might impact early events in bacillary transmission and host colonization (Woolhiser et al. 2007; Bacon et al. 2014).

Although direct evidence is lacking for the relevance of a nonreplicating state to the extended duration of anti-TB therapy, there is consensus that confining assessments of inhibitory activities to actively replicating bacilli in media comprising rich mixtures of carbon sources under aerobic conditions prejudices the outcome of compound screens (Dartois and Barry 2013; Goldman 2013). As a result, there has been considerable interest in the development of simulated microenvironmental conditions, which elicit a state of "nonreplicating persistence." For example, the combination of reactive nitrogen intermediates, acid, hypoxia, and butyrate as sole carbon source has identified agents active against both replicating and nonreplicating $M$. tuberculosis (de Carvalho et al. 2011; Gold et al. 2012), whereas a carbon starvation model also yielded novel small molecules that are active against metabolically quiescent bacilli (Grant et al. 2013). It is worth noting that, in the latter study, a comparison of the activities of a panel of hit compounds across three different in vitro models of hypoxia and nonreplicating persistence revealed differences in efficacy, suggesting that the phenotypically tolerant state conceals potentially significant variations in the underlying bacterial physiology, a disturbing possibility that requires further investigation. 
D.F. Warner

The Metabolic Response to Drug Treatment

Metabolomics has the potential to provide pharmacokinetic and pharmacodynamic information from the treated mycobacterial cell (de Carvalho et al. 2011; Chakraborty et al. 2013). For this reason, these techniques have been especially useful in determining the systems-level impact of drug treatment on $M$. tuberculosis physiology, providing key insights into the mechanisms of action of new (de Carvalho et al. 2011; Halouska et al. 2012) and even established (Halouska et al. 2013; Prosser and de Carvalho 2013) anti-TB drugs. For example, it was generally assumed that the second-line antiTB drug, para-aminosalicylic acid (PAS), competitively inhibits the essential dihydropteroate synthase in folate metabolism by acting as a mimetic of the natural enzyme substrate, paminobenzoate. However, recent analyses have instead established that PAS is a prodrug (Chakraborty et al. 2013) whose active product, a hydroxyl dihydrofolate antimetabolite, inhibits the activity of another essential enzyme in folate metabolism, dihydrofolate reductase (Zheng et al. 2013).

In a complementary approach, systems-level analyses have been increasingly applied to investigate mycobacterial mechanisms of resistance to anti-TB drugs (Kumar et al. 2013), as well as to elucidate the effect of common drugresistance mutations on bacillary physiology and cell function and, by implication, pathogenesis (Bisson et al. 2012; du Preez and Loots 2012; Loots 2014). For example, proteomic profiling of $M$. tuberculosis isolates resistant to kanamycin and amikacin implicated putative iron homeostatic proteins as well as proteins of unknown function in the metabolic adaptation of mutants resistant to the major second-line aminoglycosides (Kumar et al. 2013). Moreover, comparative proteomics of clinical rifampicinresistant isolates has revealed differences in the expression profiles of specific $r p o B$ mutants of the $M t b$ Haarlem and Beijing lineages compared with corresponding drug-susceptible counterparts (Bisson et al. 2012). Of special interest, distinct alterations were identified in the biosynthesis and regulation of phthiocerol di- mycocerosate, a methyl-branched fatty acid that has been implicated in mycobacterial virulence (Jackson et al. 2007). In related analyses of in vitro-selected rifampicin-resistant mutants with distinct $r p o B$ mutations, the investigators were able to differentiate the respective $r p o B$ mutants from one other as well as the parental strain based on fatty acid composition ( $\mathrm{du}$ Preez and Loots 2012). Moreover, follow-up work from the same laboratory suggests that a metabolic shift in isoniazid-resistant mutants ameliorates the increased vulnerability to oxidative stress that is consequent on kat $G$ mutations (Loots 2014). In combination, these results hint at a potential physiological effect of resistance that might be independent of drug selection (Koch et al. 2014); however, further research is required to test this hypothesis.

\section{FUTURE RESEARCH}

The increasing availability of whole-genome sequence data has enabled crucial insights into the evolution, epidemiology, population structure, and diversity of $M$. tuberculosis and related pathogenic and nonpathogenic mycobacteria (Ford et al. 2012). In addition to identifying unexpected genome plasticity in M. tuberculosis (Domenech et al. 2010; Weiner et al. 2012a; Shitikov et al. 2014), these analyses have established that chromosomal rearrangements and point mutations drive the genetic adaptation of M. tuberculosis within its narrow ecological niche. Some nonsynonymous mutations and insertion-deletion events represent known drug-resistance alleles (Farhat et al. 2013; Zhang et al. 2013a; Casali et al. 2014) or are likely to be inactivating (Tsolaki et al. 2004; Keating et al. 2005; Warner et al. 2007); for the majority of genomic mutations and rearrangements, however, predicting the impact of specific polymorphisms on the function of the encoded proteins remains a major challenge (Golby et al. 2013; Rose et al. 2013) and is exacerbated where multiple mutations differentiate the strain of interest from the parental isolate. Moreover, evidence of a functional consequence of a synonymous single-nucleotide polymorphism reinforces the complexity of inferring the relative 
"importance" (and impact) of observed genomic mutations from sequence data alone (Golby et al. 2013).

One possible approach to functional analysis has been suggested by recent work that used metabolomic footprinting to investigate the adaptation of clonal isolates of Pseudomonas aeruginosa collected serially during long-term infections of cystic fibrosis patients (Behrends et al. 2013). This study revealed metabolic adaptations during long-term colonization, including decreased acetate production and evolution of systems for amino acid scavenging. For pathogenic mycobacteria, there have been promising attempts to adapt a commercial platform (Biolog Phenotype Microarray) to generate phenotypic profiles based on the differential abilities of individual lineages and/or strains to use a variety of defined nutrient sources during growth in vitro (Khatri et al. 2013). It seems likely, though, that the development of methods to assign genotype-phenotype correlations, including the impact of mutations on the hostpathogen interaction, for large strain panels will be an active area of future research.

As noted elsewhere (Rhee et al. 2011), the profound disconnection between in vitro growth models and the in vivo life cycle of $M$. tuberculosis as obligate pathogen represents a critical limitation on current attempts to understand the impact of mycobacterial metabolism on the host-pathogen interaction; whereas experimental models of $M$. tuberculosis pathogenesis are largely designed to investigate the ability of the organism to persist under a variety of imposed stresses such as hypoxia, low $\mathrm{pH}$, and nutrient limitation (each of which can induce a state of nonreplication), metabolic and physiological processes are analyzed almost exclusively during active aerobic growth at maximal rates. It will be necessary, therefore, to explore the metabolic state of $M$. tuberculosis in the in vitro systems that recapitulate some of these stresses (Beste and McFadden 2010; Boshoff and Lun 2010; Rhee et al. 2011), including those that allow tighter regulation of the mycobacterial replication rate (Beste et al. 2005). In addition, the development of nonhuman primate models, including macaque (Lin et al. 2013; Mattila et al.
2013) and marmoset (Via et al. 2013), offers the prospect of experimentally tractable in vivo systems for the application of metabolomic analyses in combination with other "omics" techniques to generate true systems biology insight (Galagan et al. 2013). The parallel generation of advanced in silico models that incorporate data from a range of experimental models will be critical to interpret the emerging data and to the generation of translational algorithms that could enable predictions of metabolic states in clinical disease (Bonde et al. 2011), as well as for comparative analyses of the differential metabolic capacities of mycobacterial species and lineages (Lofthouse et al. 2013).

Space constraints dictated that many important aspects of metabolism were ignored in this review. Paramount among these are the signals and signaling mechanisms that regulate metabolic adaptations to different host environments, as well as the transcriptional and posttranslational events that enable the mycobacterial metabolic network to tolerate the perturbations that must inevitably be encountered during host infection. There is increasing evidence that noncoding RNAs are key to the regulation and function of certain metabolic pathways in M. tuberculosis (Arnvig et al. 2011; Golby et al. 2013; Li et al. 2013). Moreover, recent observations that specific intergenic regions are essential for mycobacterial survival (Zhang et al. 2012) or are involved in the emergence of drug resistance (Zhang et al. 2013a) hint at a further level of regulation that remains largely unexplored. Metabolic state can also be regulated by other factors; for example, data from $E$. coli suggest that growth-rate dependent alterations in mRNA stability modulate tricarboxylic cycle activity (Esquerre et al. 2013). The possibility, therefore, that the unusually stable transcripts (Rustad et al. 2013) characteristic of a slow-growing pathogen have evolved for specific regulatory functions is likely to be tested in future investigations.

The historical term for TB was "consumption" (Schwenk and Macallan 2000), which eloquently encapsulated the physical effects of the disease on the afflicted patient during its terminal stages. Although I have highlighted some of 
D.F. Warner

the consequences of $M$. tuberculosis infection for host function, particularly those relating to the accumulation of fatty acid stores in infected macrophages, the precise mechanisms mediating the observed metabolic dysfunction in TB disease are poorly understood. Therefore, although considerable effort is spent on developing host-directed therapies targeting immune functions, recent evidence (Gouzy et al. 2013; Zhang et al. 2013b) suggests that a deeper understanding of the metabolic factors that influence the outcome of the M. tuberculosis-host interaction might offer a profitable source of novel anti-TB interventions.

\section{ACKNOWLEDGMENTS}

I thank Krishnamoorthy Gopinath for useful discussions, Raju Mukherjee and Vinayak Singh for some helpful suggestions, and Valerie Mizrahi for critical review of the manuscript. Work in the Molecular Mycobacteriology Research Unit is enabled by core financial support from the South African Medical Research Council, the National Research Foundation (NRF) of South Africa, and the University of Cape Town. Research on vitamin $B_{12}$ metabolism is funded by the NRF South Africa (grant number CPRR13091339569) and a Senior International Research Scholar's grant (to V. Mizrahi).

\section{REFERENCES}

${ }^{*}$ Reference is also in this subject collection.

Abrahams GL, Kumar A, Savvi S, Hung AW, Wen S, Abell C, Barry CE 3rd, Sherman DR, Boshoff HI, Mizrahi V. 2012. Pathway-selective sensitization of Mycobacterium tuberculosis for target-based whole-cell screening. Chem Biol 19: $844-854$.

Agarwal N, Lamichhane G, Gupta R, Nolan S, Bishai WR. 2009. Cyclic AMP intoxication of macrophages by a $M y$ cobacterium tuberculosis adenylate cyclase. Nature 460: 98-102.

* Alderwick LJ, Harrison J, Lloyd GS, Birch HL. 2014. The mycobacterial cell wall-Peptidoglycan and arabinogalactan. Cold Spring Harb Perspect Med doi: 10.1101/ cshperspect.a021113.

Arnvig KB, Comas I, Thomson NR, Houghton J, Boshoff HI, Croucher NJ, Rose G, Perkins TT, Parkhill J, Dougan $\mathrm{G}$, et al. 2011. Sequence-based analysis uncovers an abundance of non-coding RNA in the total transcrip- tome of Mycobacterium tuberculosis. PLoS Pathog 7: e1002342.

Bacon J, Alderwick LJ, Allnutt JA, Gabasova E, Watson R, Hatch KA, Clark SO, Jeeves RE, Marriott A, Rayner E, et al. 2014. Non-replicating Mycobacterium tuberculosis elicits a reduced infectivity profile with corresponding modifications to the cell wall and extracellular matrix. PLOS ONE 9: e87329.

Baek SH, Li AH, Sassetti CM. 2011. Metabolic regulation of mycobacterial growth and antibiotic sensitivity. PLoS Biol 9: e1001065.

Barrios-Payan J, Saqui-Salces M, Jeyanathan M, AlcantaraVazquez A, Castanon-Arreola M, Rook G, HernandezPando R. 2012. Extrapulmonary locations of Mycobacterium tuberculosis DNA during latent infection. J Infect Dis 206: 1194-1205.

Barry CE 3rd, Boshoff HI, Dartois V, Dick T, Ehrt S, Flynn J, Schnappinger D, Wilkinson RJ, Young D. 2009. The spectrum of latent tuberculosis: Rethinking the biology and intervention strategies. Nat Rev Microbiol 7: 845-855.

Baruch M, Belotserkovsky I, Hertzog BB, Ravins M, Dov E, McIver KS, Le Breton YS, Zhou Y, Chen CY, Hanski E. 2014. An extracellular bacterial pathogen modulates host metabolism to regulate its own sensing and proliferation. Cell 156: $97-108$.

Baughn AD, Garforth SJ, Vilcheze C, Jacobs WR Jr., 2009. An anaerobic-type $\alpha$-ketoglutarate ferredoxin oxidoreductase completes the oxidative tricarboxylic acid cycle of Mycobacterium tuberculosis. PLoS Pathog 5: e1000662.

Behrends V, Ryall B, Zlosnik JE, Speert DP, Bundy JG, Williams HD. 2013. Metabolic adaptations of Pseudomonas aeruginosa during cystic fibrosis chronic lung infections. Environ Microbiol 15: 398-408.

Berg IA, Filatova LV, Ivanovsky RN. 2002. Inhibition of acetate and propionate assimilation by itaconate via propionyl-CoA carboxylase in isocitrate lyase-negative purple bacterium Rhodospirillum rubrum. FEMS microbiology letters 216: $49-54$.

Beste DJ, McFadden J. 2010. System-level strategies for studying the metabolism of Mycobacterium tuberculosis. Mol Biosyst 6: 2363-2372.

Beste DJ, Peters J, Hooper T, Avignone-Rossa C, Bushell ME, McFadden J. 2005. Compiling a molecular inventory for Mycobacterium bovis BCG at two growth rates: Evidence for growth rate-mediated regulation of ribosome biosynthesis and lipid metabolism. J Bacteriol 187: 1677-1684.

Beste DJ, Bonde B, Hawkins N, Ward JL, Beale MH, Noack S Noh K, Kruger NJ, Ratcliffe RG, McFadden J. 2011. ${ }^{13} \mathrm{C}$ metabolic flux analysis identifies an unusual route for pyruvate dissimilation in mycobacteria which requires isocitrate lyase and carbon dioxide fixation. PLoS Pathog 7: e1002091.

Beste DJ, Noh K, Niedenfuhr S, Mendum TA, Hawkins ND, Ward JL, Beale MH, Wiechert W, McFadden J. 2013. ${ }^{13} \mathrm{C}$-flux spectral analysis of host-pathogen metabolism reveals a mixed diet for intracellular Mycobacterium tuberculosis. Chem Biol 20: 1012-1021.

Bisson GP, Mehaffy C, Broeckling C, Prenni J, Rifat D, Lun DS, Burgos M, Weissman D, Karakousis PC, Dobos K. 2012. Upregulation of the phthiocerol dimycocerosate biosynthetic pathway by rifampin-resistant, $r p o B$ mutant Mycobacterium tuberculosis. J Bacteriol 194: 6441-6452. 
Blumenthal A, Trujillo C, Ehrt S, Schnappinger D. 2010. Simultaneous analysis of multiple Mycobacterium tuberculosis knockdown mutants in vitro and in vivo. PLoS ONE 5: e15667.

Bonde BK, Beste DJ, Laing E, Kierzek AM, McFadden J. 2011. Differential producibility analysis (DPA) of transcriptomic data with metabolic networks: Deconstructing the metabolic response of M. tuberculosis. PLoS Comput Biol 7: e1002060.

Boshoff HI, Barry CE 3rd. 2005. Tuberculosis-Metabolism and respiration in the absence of growth. Nat Rev Microbiol 3: 70-80.

Boshoff HI, Lun DS. 2010. Systems biology approaches to understanding mycobacterial survival mechanisms. Drug Discov Today Dis Mech 7: e75-e82.

Botella H, Peyron P, Levillain F, Poincloux R, Poquet Y, Brandli I, Wang C, Tailleux L, Tilleul S, Charriere GM, et al. 2011. Mycobacterial $\mathrm{P}_{1}$-type ATPases mediate resistance to zinc poisoning in human macrophages. Cell Host Microbe 10: 248-259.

Brinster S, Lamberet G, Staels B, Trieu-Cuot P, Gruss A, Poyart C. 2009. Type II fatty acid synthesis is not a suitable antibiotic target for Gram-positive pathogens. Nature 458: 83-86.

Brodin P, Poquet Y, Levillain F, Peguillet I, Larrouy-Maumus G, Gilleron M, Ewann F, Christophe T, Fenistein D, Jang J, et al. 2010. High content phenotypic cell-based visual screen identifies Mycobacterium tuberculosis acyltrehalose-containing glycolipids involved in phagosome remodeling. PLoS Pathog 6: e1001100.

Bryk R, Gold B, Venugopal A, Singh J, Samy R, Pupek K, Cao H, Popescu C, Gurney M, Hotha S, et al. 2008. Selective killing of nonreplicating mycobacteria. Cell Host Microbe 3: $137-145$.

Bryk R, Arango N, Maksymiuk C, Balakrishnan A, Wu YT, Wong CH, Masquelin T, Hipskind P, Lima CD, Nathan C. 2013. Lipoamide channel-binding sulfonamides selectively inhibit mycobacterial lipoamide dehydrogenase. Biochemistry 52: 9375-9384.

Casali N, Nikolayevskyy V, Balabanova Y, Harris SR, Ignatyeva O, Kontsevaya I, Corander J, Bryant J, Parkhill J, Nejentsev S, et al. 2014. Evolution and transmission of drug-resistant tuberculosis in a Russian population. Nat Genet 46: 279-286.

Chakraborty S, Gruber T, Barry CE 3rd, Boshoff HI, Rhee KY. 2013. Para-aminosalicylic acid acts as an alternative substrate of folate metabolism in Mycobacterium tuberculosis. Science 339: 88-91.

Chambers MA, Williams A, Gavier-Widen D, Whelan A, Hall G, Marsh PD, Bloom BR, Jacobs WR, Hewinson RG. 2000. Identification of a Mycobacterium bovis BCG auxotrophic mutant that protects guinea pigs against M. bovis and hematogenous spread of Mycobacterium tuberculosis without sensitization to tuberculin. Infect Immun 68: 7094-7099.

Cho SH, Warit S, Wan B, Hwang CH, Pauli GF, Franzblau SG. 2007. Low-oxygen-recovery assay for high-throughput screening of compounds against nonreplicating $M y$ cobacterium tuberculosis. Antimicrob Agents Chemother 51: $1380-1385$.

Christophe T, Jackson M, Jeon HK, Fenistein D, ContrerasDominguez M, Kim J, Genovesio A, Carralot JP, Ewann F,
Kim EH, et al. 2009. High content screening identifies decaprenyl-phosphoribose $2^{\prime}$ epimerase as a target for intracellular antimycobacterial inhibitors. PLoS Pathog 5: e1000645.

Cole ST, Brosch R, Parkhill J, Garnier T, Churcher C, Harris D, Gordon SV, Eiglmeier K, Gas S, Barry CE 3rd, et al. 1998. Deciphering the biology of Mycobacterium tuberculosis from the complete genome sequence. Nature 393: 537-544.

Comas I, Chakravartti J, Small PM, Galagan J, Niemann S, Kremer K, Ernst JD, Gagneux S. 2010. Human T cell epitopes of Mycobacterium tuberculosis are evolutionarily hyperconserved. Nat Genet 42: 498-503.

Comas I, Coscolla M, Luo T, Borrell S, Holt KE, Kato-Maeda M, Parkhill J, Malla B, Berg S, Thwaites G, et al. 2013. Out-of-Africa migration and Neolithic coexpansion of Mycobacterium tuberculosis with modern humans. Nat Genet 45: 1176-1182.

Daniel J, Maamar H, Deb C, Sirakova TD, Kolattukudy PE. 2011. Mycobacterium tuberculosis uses host triacylglycerol to accumulate lipid droplets and acquires a dormancylike phenotype in lipid-loaded macrophages. PLoS Pathog 7: e1002093.

Dartois V. 2014. The path of anti-tuberculosis drugs: From blood to lesions to mycobacterial cells. Nat Rev Microbiol 12: $159-167$.

Dartois V, Barry CE 3rd. 2013. A medicinal chemists' guide to the unique difficulties of lead optimization for tuberculosis. Bioorg Med Chem Lett 23: 4741-4750.

de Carvalho LP, Lin G, Jiang X, Nathan C. 2009. Nitazoxanide kills replicating and nonreplicating Mycobacterium tuberculosis and evades resistance. J Med Chem 52: 57895792.

de Carvalho LP, Fischer SM, Marrero J, Nathan C, Ehrt S, Rhee KY. 2010a. Metabolomics of Mycobacterium tuberculosis reveals compartmentalized co-catabolism of carbon substrates. Chem Biol 17: 1122-1131.

de Carvalho LP, Zhao H, Dickinson CE, Arango NM, Lima CD, Fischer SM, Ouerfelli O, Nathan C, Rhee KY. 2010b. Activity-based metabolomic profiling of enzymatic function: Identification of Rv1248c as a mycobacterial 2-hydroxy-3-oxoadipate synthase. Chem Biol 17: 323-332.

de Carvalho LP, Darby CM, Rhee KY, Nathan C. 2011. Nitazoxanide disrupts membrane potential and intrabacterial $\mathrm{pH}$ homeostasis of Mycobacterium tuberculosis. ACS Med Chem Lett 2: 849-854.

Domenech P, Kolly GS, Leon-Solis L, Fallow A, Reed MB. 2010. Massive gene duplication event among clinical isolates of the Mycobacterium tuberculosis W/Beijing family. J Bacteriol 192: 4562-4570.

du Preez I, Loots D. 2012. Altered fatty acid metabolism due to rifampicin-resistance conferring mutations in the $r p o B$ gene of Mycobacterium tuberculosis: Mapping the potential of pharmaco-metabolomics for global health and personalized medicine. Omics 16: 596-603.

du Preez I, Loots DT. 2013. New sputum metabolite markers implicating adaptations of the host to Mycobacterium tuberculosis, and vice versa. Tuberculosis (Edinb) 93: 330-337.

Duckworth BP, Geders TW, Tiwari D, Boshoff HI, Sibbald PA, Barry CE 3rd, Schnappinger D, Finzel BC, Aldrich CC. 2011. Bisubstrate adenylation inhibitors of biotin 
D.F. Warner

protein ligase from Mycobacterium tuberculosis. Chem Biol 18: 1432-1441.

Ehrt S, Guo XV, Hickey CM, Ryou M, Monteleone M, Riley LW, Schnappinger D. 2005. Controlling gene expression in mycobacteria with anhydrotetracycline and Tet repressor. Nucleic Acids Res 33: e21.

Eoh H, Rhee KY. 2013. Multifunctional essentiality of succinate metabolism in adaptation to hypoxia in Mycobacterium tuberculosis. Proc Natl Acad Sci 110: 6554-6559.

Ernst JD. 2012. The immunological life cycle of tuberculosis. Nat Rev Immunol 12: 581-591.

Esquerre T, Laguerre S, Turlan C, Carpousis AJ, Girbal L, Cocaign-Bousquet M. 2013. Dual role of transcription and transcript stability in the regulation of gene expression in Escherichia coli cells cultured on glucose at different growth rates. Nucleic Acids Res 42: 2460-2472.

Eum SY, Kong JH, Hong MS, Lee YJ, Kim JH, Hwang SH, Cho SN, Via LE, Barry CE 3rd. 2010. Neutrophils are the predominant infected phagocytic cells in the airways of patients with active pulmonary TB. Chest 137: 122-128.

Farhat MR, Shapiro BJ, Kieser K, Sultana R, Jacobson KR, Victor TC, Warren RM, Streicher EM, Calver A, Sloutsky A, et al. 2013. Genomic analysis identifies targets of convergent positive selection in drug resistant Mycobacterium tuberculosis. Nat Genet 45: 1183-1189.

Ford CB, Lin PL, Chase MR, Shah RR, Iartchouk O, Galagan J, Mohaideen N, Ioerger TR, Sacchettini JC, Lipsitch M, et al. 2011. Use of whole genome sequencing to estimate the mutation rate of Mycobacterium tuberculosis during latent infection. Nat Genet 43: 482-486.

Ford C, Yusim K, Ioerger T, Feng S, Chase M, Greene M, Korber B, Fortune S. 2012. Mycobacterium tuberculosisHeterogeneity revealed through whole genome sequencing. Tuberculosis (Edinb) 92: 194-201.

Franzblau SG, DeGroote MA, Cho SH, Andries K, Nuermberger E, Orme IM, Mdluli K, Angulo-Barturen I, Dick T, Dartois V, et al. 2012. Comprehensive analysis of methods used for the evaluation of compounds against Mycobacterium tuberculosis. Tuberculosis (Edinb) 92: 453-488.

Galagan JE, Minch K, Peterson M, Lyubetskaya A, Azizi E, Sweet L, Gomes A, Rustad T, Dolganov G, Glotova I, et al 2013. The Mycobacterium tuberculosis regulatory network and hypoxia. Nature 499: 178-183.

Garton NJ, Waddell SJ, Sherratt AL, Lee SM, Smith RJ, Senner C, Hinds J, Rajakumar K, Adegbola RA, Besra GS, et al. 2008. Cytological and transcript analyses reveal fat and lazy persister-like bacilli in tuberculous sputum. PLoS Med 5: e75.

Gill WP, Harik NS, Whiddon MR, Liao RP, Mittler JE, Sherman DR. 2009. A replication clock for Mycobacterium tuberculosis. Nat Med 15: 211-214.

Golby P, Nunez J, Witney A, Hinds J, Quail MA, Bentley S, Harris S, Smith N, Hewinson RG, Gordon SV. 2013. Genome-level analyses of Mycobacterium bovis lineages reveal the role of SNPs and antisense transcription in differential gene expression. BMC Genomics 14: 710.

Gold B, Pingle M, Brickner SJ, Shah N, Roberts J, Rundell M, Bracken WC, Warrier T, Somersan S, Venugopal A, et al. 2012. Nonsteroidal anti-inflammatory drug sensitizes Mycobacterium tuberculosis to endogenous and exogenous antimicrobials. Proc Natl Acad Sci 109: 1600416011.
Goldman RC. 2013. Why are membrane targets discovered by phenotypic screens and genome sequencing in $\mathrm{Myco-}$ bacterium tuberculosis? Tuberculosis (Edinb) 93: 569-588.

Gopinath K, Moosa A, Mizrahi V, Warner DF. 2013a. Vitamin $\mathrm{B}_{12}$ metabolism in Mycobacterium tuberculosis. Future Microbiol 8: 1405-1418.

Gopinath K, Venclovas C, Ioerger TR, Sacchettini JC, McKinney JD, Mizrahi V, Warner DF. 2013b. A vitamin $B_{12}$ transporter in Mycobacterium tuberculosis. Open Biol 3: 120175.

Gordhan BG, Smith DA, Alderton H, McAdam RA, Bancroft GJ, Mizrahi V. 2002. Construction and phenotypic characterization of an auxotrophic mutant of Mycobacterium tuberculosis defective in L-arginine biosynthesis. Infect Immun 70: 3080-3084.

Gouzy A, Larrouy-Maumus G, Wu TD, Peixoto A, Levillain F, Lugo-Villarino G, Gerquin-Kern JL, de Carvalho LP, Poquet Y, Neyrolles O. 2013. Mycobacterium tuberculosis nitrogen assimilation and host colonization require aspartate. Nat Chem Biol 9: 674-676.

Gouzy A, Larrouy-Maumus G, Bottai D, Levillain F, Dumas A, Wallach JB, Caire-Brandli I, de Chastellier C, Wu TD, Poincloux R, et al. 2014. Mycobacterium tuberculosis exploits asparagine to assimilate nitrogen and resist acid stress during Infection. PLoS Pathog 10: e1003928.

Grant SS, Kawate T, Nag PP, Silvis MR, Gordon K, Stanley SA, Kazyanskaya E, Nietupski R, Golas A, Fitzgerald M, et al. 2013. Identification of novel inhibitors of nonreplicating Mycobacterium tuberculosis using a carbon starvation model. ACS Chem Biol 8: 2224-2234.

Griffin JE, Gawronski JD, Dejesus MA, Ioerger TR, Akerley BJ, Sassetti CM. 2011. High-resolution phenotypic profiling defines genes essential for mycobacterial growth and cholesterol catabolism. PLoS Pathog 7: e1002251.

Griffin JE, Pandey AK, Gilmore SA, Mizrahi V, McKinney JD, Bertozzi CR, Sassetti CM. 2012. Cholesterol catabolism by Mycobacterium tuberculosis requires transcriptional and metabolic adaptations. Chem Biol 19: 218227.

Halouska S, Fenton RJ, Barletta RG, Powers R. 2012. Predicting the in vivo mechanism of action for drug leads using NMR metabolomics. ACS Chem Biol 7: 166-171.

Halouska S, Fenton RJ, Zinniel DK, Marshall DD, Barletta RG, Powers R. 2013. Metabolomics analysis identifies D-alanine-D-alanine ligase as the primary lethal target of D-cycloserine in mycobacteria. J Proteome Res 13: 1065-1076.

Hawn TR, Matheson AI, Maley SN, Vandal O. 2013. Hostdirected therapeutics for tuberculosis: Can we harness the host? Microbiol Mol Biol Rev 77: 608-627.

Hernandez-Pando R, Jeyanathan M, Mengistu G, Aguilar D, Orozco H, Harboe M, Rook GA, Bjune G. 2000. Persistence of DNA from Mycobacterium tuberculosis in superficially normal lung tissue during latent infection. Lancet 356: $2133-2138$.

Hingley-Wilson SM, Sambandamurthy VK, Jacobs WR Jr., 2003. Survival perspectives from the world's most successful pathogen, Mycobacterium tuberculosis. Nat Immunol 4: 949-955.

Hinshelwood S, Stoker NG. 1992. Cloning of mycobacterial histidine synthesis genes by complementation of a $\mathrm{Myco}$ - 
bacterium smegmatis auxotroph. Mol Microbiol 6: $2887-$ 2895.

Hu Y, Movahedzadeh F, Stoker NG, Coates AR. 2006. Deletion of the Mycobacterium tuberculosis $\alpha$-crystallin-like $h s p X$ gene causes increased bacterial growth in vivo. Infect Immun 74: 861-868.

Ishii N, Nakahigashi K, Baba T, Robert M, Soga T, Kanai A, Hirasawa T, Naba M, Hirai K, Hoque A, et al. 2007. Multiple high-throughput analyses monitor the response of E. coli to perturbations. Science 316: 593-597.

* Jackson M. 2014. The mycobacterial cell envelope-Lipids. Cold Spring Harb Perspect Med 4: a021105.

Jackson M, Stadthagen G, Gicquel B. 2007. Long-chain multiple methyl-branched fatty acid-containing lipids of $M y$ cobacterium tuberculosis: Biosynthesis, transport, regulation and biological activities. Tuberculosis (Edinb) 87: 78-86.

Jain M, Petzold CJ, Schelle MW, Leavell MD, Mougous JD, Bertozzi CR, Leary JA, Cox JS. 2007. Lipidomics reveals control of Mycobacterium tuberculosis virulence lipids via metabolic coupling. Proc Natl Acad Sci 104: 51335138.

Jayaswal S, Kamal MA, Dua R, Gupta S, Majumdar T, Das G, Kumar D, Rao KV. 2010. Identification of host-dependent survival factors for intracellular Mycobacterium tuberculosis through an siRNA screen. PLoS Pathog 6: e1000839.

Kalscheuer R, Weinrick B, Veeraraghavan U, Besra GS, Jacobs WR Jr., 2010. Trehalose-recycling ABC transporter LpqY-SugA-SugB-SugC is essential for virulence of $M y$ cobacterium tuberculosis. Proc Natl Acad Sci 107: 21761 21766.

Kaplan G, Post FA, Moreira AL, Wainwright H, Kreiswirth BN, Tanverdi M, Mathema B, Ramaswamy SV, Walther G, Steyn LM, et al. 2003. Mycobacterium tuberculosis growth at the cavity surface: A microenvironment with failed immunity. Infect Immun 71: 7099-7108.

Karakousis PC, Williams EP, Bishai WR. 2008. Altered expression of isoniazid-regulated genes in drug-treated dormant Mycobacterium tuberculosis. J Antimicrob Chemother 61: 323-331.

Keating LA, Wheeler PR, Mansoor H, Inwald JK, Dale J, Hewinson RG, Gordon SV. 2005. The pyruvate requirement of some members of the Mycobacterium tuberculosis complex is due to an inactive pyruvate kinase: Implications for in vivo growth. Mol Microbiol 56: 163-174.

Khatri B, Fielder M, Jones G, Newell W, Abu-Oun M, Wheeler PR. 2013. High throughput phenotypic analysis of Mycobacterium tuberculosis and Mycobacterium bovis strains' metabolism using biolog phenotype microarrays. PLOS ONE 8: e52673.

Kim MJ, Wainwright HC, Locketz M, Bekker LG, Walther GB, Dittrich C, Visser A, Wang W, Hsu FF, Wiehart U, et al. 2010. Caseation of human tuberculosis granulomas correlates with elevated host lipid metabolism. EMBO Mol Med 2: 258-274.

Kim JH, O’Brien KM, Sharma R, Boshoff HI, Rehren G, Chakraborty S, Wallach JB, Monteleone M, Wilson DJ, Aldrich CC, et al. 2013. A genetic strategy to identify targets for the development of drugs that prevent bacterial persistence. Proc Natl Acad Sci 110: 19095-19100.
Kjer-Nielsen L, Patel O, Corbett AJ, Le Nours J, Meehan B, Liu L, Bhati M, Chen Z, Kostenko L, Reantragoon R, et al. 2012. MR1 presents microbial vitamin B metabolites to MAIT cells. Nature 491: 717-723.

Koch A, Mizrahi V, Warner DF. 2014. The impact of drug resistance on Mycobacterium tuberculosis physiology: What can we learn from rifampicin? Emerg Microb Infect 3: e17.

Kolly GS, Boldrin F, Sala C, Dhar N, Hartkoorn RC, Ventura M, Serafini A, McKinney JD, Manganelli R, Cole ST. 2014. Assessing the essentiality of the decaprenyl-phospho-Darabinofuranose pathway in Mycobacterium tuberculosis using conditional mutants. Mol Microbiol 92: 194-211.

Koul A, Vranckx L, Dhar N, Gohlmann HW, Ozdemir E, Neefs JM, Schulz M, Lu P, Mortz E, McKinney JD, et al. 2014. Delayed bactericidal response of Mycobacterium tuberculosis to bedaquiline involves remodelling of bacterial metabolism. Nat Commun 5: 3369.

Kumar D, Rao KV. 2011. Regulation between survival, persistence, and elimination of intracellular mycobacteria: A nested equilibrium of delicate balances. Microbes Infect 13: $121-133$.

Kumar D, Nath L, Kamal MA, Varshney A, Jain A, Singh S, Rao KV. 2010. Genome-wide analysis of the host intracellular network that regulates survival of Mycobacterium tuberculosis. Cell 140: 731-743.

Kumar B, Sharma D, Sharma P, Katoch VM, Venkatesan K, Bisht D. 2013. Proteomic analysis of Mycobacterium tuberculosis isolates resistant to kanamycin and amikacin. J Proteomics 94: 68-77.

Larrouy-Maumus G, Biswas T, Hunt DM, Kelly G, Tsodikov OV, de Carvalho LP. 2013. Discovery of a glycerol 3-phosphate phosphatase reveals glycerophospholipid polar head recycling in Mycobacterium tuberculosis. Proc Natl Acad Sci 110: 11320-11325.

Larsen MH, Biermann K, Chen B, Hsu T, Sambandamurthy VK, Lackner AA, Aye PP, Didier P, Huang D, Shao L, et al. 2009. Efficacy and safety of live attenuated persistent and rapidly cleared Mycobacterium tuberculosis vaccine candidates in non-human primates. Vaccine 27: 4709-4717.

Lechartier B, Rybniker J, Zumla A, Cole ST. 2014. Tuberculosis drug discovery in the post-post-genomic era. $E M B O$ Mol Med 6: 158-168.

Lee W, VanderVen BC, Fahey RJ, Russell DG. 2013. Intracellular Mycobacterium tuberculosis exploits host-derived fatty acids to limit metabolic stress. J Biol Chem 288: 6788-6800.

Lew JM, Mao C, Shukla M, Warren A, Will R, Kuznetsov D, Xenarios I, Robertson BD, Gordon SV, Schnappinger D, et al. 2013. Database resources for the tuberculosis community. Tuberculosis (Edinb) 93: 12-17.

Li SK, Ng PK, Qin H, Lau JK, Lau JP, Tsui SK, Chan TF, Lau TC. 2013. Identification of small RNAs in Mycobacterium smegmatis using heterologous Hfq. RNA 19: 74-84.

Lin PL, Rodgers M, Smith L, Bigbee M, Myers A, Bigbee C, Chiosea I, Capuano SV, Fuhrman C, Klein E, et al. 2009. Quantitative comparison of active and latent tuberculosis in the cynomolgus macaque model. Infect Immun 77: $4631-4642$.

Lin PL, Ford CB, Coleman MT, Myers AJ, Gawande R, Ioerger T, Sacchettini J, Fortune SM, Flynn JL. 2013. Sterilization of granulomas is common in active and latent 
D.F. Warner

tuberculosis despite within-host variability in bacterial killing. Nat Med 20: 75-79

Lofthouse EK, Wheeler PR, Beste DJ, Khatri BL, Wu H, Mendum TA, Kierzek AM, McFadden J. 2013. Systemsbased approaches to probing metabolic variation within the Mycobacterium tuberculosis complex. PLoS ONE 8: e75913.

Loots DT. 2014. An altered Mycobacterium tuberculosis metabolome induced by kat $G$ mutations resulting in isoniazid resistance. Antimicrob Agents Chemother 58: 2144-2149.

Lowe DM, Redford PS, Wilkinson RJ, O'Garra A, Martineau AR. 2012. Neutrophils in tuberculosis: Friend or foe? Trends Immunol 33: 14-25.

Mahapatra S, Hess AM, Johnson JL, Eisenach KD, DeGroote MA, Gitta P, Joloba ML, Kaplan G, Walzl G, Boom WH, et al. 2014. A metabolic biosignature of early response to anti-tuberculosis treatment. BMC Infect Dis 14: 53.

Marrero J, Rhee KY, Schnappinger D, Pethe K, Ehrt S. 2010. Gluconeogenic carbon flow of tricarboxylic acid cycle intermediates is critical for Mycobacterium tuberculosis to establish and maintain infection. Proc Natl Acad Sci 107: $9819-9824$.

Marrero J, Trujillo C, Rhee KY, Ehrt S. 2013. Glucose phosphorylation is required for Mycobacterium tuberculosis persistence in mice. PLoS Pathog 9: e1003116.

Mattila JT, Ojo OO, Kepka-Lenhart D, Marino S, Kim JH, Eum SY, Via LE, Barry CE 3rd, Klein E, Kirschner DE, et al. 2013. Microenvironments in tuberculous granulomas are delineated by distinct populations of macrophage subsets and expression of nitric oxide synthase and arginase isoforms. J Immunol 191: 773-784.

McAdam RA, Weisbrod TR, Martin J, Scuderi JD, Brown AM, Cirillo JD, Bloom BR, Jacobs WR Jr., 1995. In vivo growth characteristics of leucine and methionine auxotrophic mutants of Mycobacterium bovis BCG generated by transposon mutagenesis. Infect Immun 63: 10041012.

McGuire AM, Weiner B, Park ST, Wapinski I, Raman S, Dolganov G, Peterson M, Riley R, Zucker J, Abeel T, et al. 2012. Comparative analysis of mycobacterium and related actinomycetes yields insight into the evolution of Mycobacterium tuberculosis pathogenesis. BMC Genomics 13: 120.

McKinney JD, Honer zu Bentrup K, Munoz-Elias EJ, Miczak A, Chen B, Chan WT, Swenson D, Sacchettini JC, Jacobs WR Jr., Russell DG. 2000. Persistence of Mycobacterium tuberculosis in macrophages and mice requires the glyoxylate shunt enzyme isocitrate lyase. Nature 406: 735-738.

Michelucci A, Cordes T, Ghelfi J, Pailot A, Reiling N, Goldmann O, Binz T, Wegner A, Tallam A, Rausell A, et al. 2013. Immune-responsive gene 1 protein links metabolism to immunity by catalyzing itaconic acid production. Proc Natl Acad Sci 110: 7820-7825.

Molle V, Kremer L. 2010. Division and cell envelope regulation by Ser/Thr phosphorylation: Mycobacterium shows the way. Mol Microbiol 75: 1064-1077.

Munoz-Elias EJ, McKinney JD. 2005. Mycobacterium tuberculosis isocitrate lyases 1 and 2 are jointly required for in vivo growth and virulence. Nat Med 11: 638-644.

Munoz-Elias EJ, McKinney JD. 2006. Carbon metabolism of intracellular bacteria. Cell Microbiol 8: 10-22.
Munoz-Elias EJ, Upton AM, Cherian J, McKinney JD. 2006. Role of the methylcitrate cycle in Mycobacterium tuberculosis metabolism, intracellular growth, and virulence. Mol Microbiol 60: 1109-1122.

O'Garra A, Redford PS, McNab FW, Bloom CI, Wilkinson RJ, Berry MP. 2013. The immune response in tuberculosis. Annu Rev Immunol 31: 475-527.

Olivier I, Loots D. 2012. A metabolomics approach to characterise and identify various Mycobacterium species. $J$ Microbiol Methods 88: 419-426.

Owens CP, Chim N, Graves AB, Harmston CA, Iniguez A, Contreras H, Liptak MD, Goulding CW. 2013. The Mycobacterium tuberculosis secreted protein Rv0203 transfers heme to membrane proteins MmpL3 and MmpL11.J Biol Chem 288: 21714-21728.

Pandey AK, Sassetti CM. 2008. Mycobacterial persistence requires the utilization of host cholesterol. Proc Natl Acad Sci 105: 4376-4380.

Parish T. 2003. Starvation survival response of Mycobacterium tuberculosis. J Bacteriol 185: 6702-6706.

Parish T, Smith DA, Kendall S, Casali N, Bancroft GJ, Stoker NG. 2003. Deletion of two-component regulatory systems increases the virulence of Mycobacterium tuberculosis. Infect Immun 71: 1134-1140.

Pavelka MS Jr., Chen B, Kelley CL, Collins FM, Jacobs WR Jr., 2003. Vaccine efficacy of a lysine auxotroph of $\mathrm{Myco-}$ bacterium tuberculosis. Infect Immun 71: 4190-4192.

Pethe K, Sequeira PC, Agarwalla S, Rhee K, Kuhen K, Phong WY, Patel V, Beer D, Walker JR, Duraiswamy J, et al. 2010 A chemical genetic screen in Mycobacterium tuberculosis identifies carbon-source-dependent growth inhibitors devoid of in vivo efficacy. Nat Commun 1: 57.

Peyron P, Vaubourgeix J, Poquet Y, Levillain F, Botanch C, Bardou F, Daffe M, Emile JF, Marchou B, Cardona PJ, et al. 2008. Foamy macrophages from tuberculous patients' granulomas constitute a nutrient-rich reservoir for M. tuberculosis persistence. PLoS Pathog 4: e1000204.

Prosser GA, de Carvalho LP. 2013. Metabolomics reveal D-alanine: D-alanine ligase as the target of D-cycloserine in Mycobacterium tuberculosis. ACS Med Chem Lett 4: $1233-1237$.

Qualls JE, Subramanian C, Rafi W, Smith AM, Balouzian L, DeFreitas AA, Shirey KA, Reutterer B, Kernbauer E, Stockinger S, et al. 2012. Sustained generation of nitric oxide and control of mycobacterial infection requires argininosuccinate synthase 1. Cell Host Microbe 12: 313-323.

Rengarajan J, Bloom BR, Rubin EJ. 2005. Genome-wide requirements for Mycobacterium tuberculosis adaptation and survival in macrophages. Proc Natl Acad Sci 102: 8327-8332.

Rhee K. 2013. Minding the gaps: Metabolomics mends functional genomics. EMBO Rep 14: 949-950.

Rhee KY, de Carvalho LPS, Bryk R, Ehrt S, Marrero J, Park SW, Schnappinger D, Venugopal A, Nathan C. 2011. Central carbon metabolism in Mycobacterium tuberculosis: An unexpected frontier. Trends Microbiol 19: 307-314.

Rohde KH, Veiga DF, Caldwell S, Balazsi G, Russell DG. 2012. Linking the transcriptional profiles and the physiological states of Mycobacterium tuberculosis during 
an extended intracellular infection. PLoS Pathog 8: e1002769.

Rose G, Cortes T, Comas I, Coscolla M, Gagneux S, Young DB. 2013. Mapping of genotype-phenotype diversity among clinical isolates of Mycobacterium tuberculosis by sequence-based transcriptional profiling. Genome Biol Evol 5: 1849-1862.

Russell DG. 2011. Mycobacterium tuberculosis and the intimate discourse of a chronic infection. Immunol Rev 240: 252-268.

Rustad TR, Minch KJ, Brabant W, Winkler JK, Reiss DJ, Baliga NS, Sherman DR. 2013. Global analysis of mRNA stability in Mycobacterium tuberculosis. Nucleic Acids Res 41: 509-517.

Sambandamurthy VK, Derrick SC, Jalapathy KV, Chen B, Russell RG, Morris SL, Jacobs WR Jr, 2005. Long-term protection against tuberculosis following vaccination with a severely attenuated double lysine and pantothenate auxotroph of Mycobacterium tuberculosis. Infect Immun 73: 1196-1203.

Sampson SL, Dascher CC, Sambandamurthy VK, Russell RG, Jacobs WR Jr, Bloom BR, Hondalus MK. 2004. Protection elicited by a double leucine and pantothenate auxotroph of Mycobacterium tuberculosis in guinea pigs. Infect Immun 72: 3031-3037.

Sampson SL, Mansfield KG, Carville A, Magee DM, Quitugua T, Howerth EW, Bloom BR, Hondalus MK. 2011. Extended safety and efficacy studies of a live attenuated double leucine and pantothenate auxotroph of Mycobacterium tuberculosis as a vaccine candidate. Vaccine 29: 4839-4847.

Sassetti CM, Rubin EJ. 2003. Genetic requirements for mycobacterial survival during infection. Proc Natl Acad Sci 100: $12989-12994$.

Sassetti CM, Boyd DH, Rubin EJ. 2003. Genes required for mycobacterial growth defined by high density mutagenesis. Mol Microbiol 48: 77-84.

Savvi S, Warner DF, Kana BD, McKinney JD, Mizrahi V, Dawes SS. 2008. Functional characterization of a vitamin $\mathrm{B}_{12}$-dependent methylmalonyl pathway in Mycobacterium tuberculosis: Implications for propionate metabolism during growth on fatty acids. J Bacteriol 190: 3886-3895.

Schnappinger D, Ehrt S, Voskuil MI, Liu Y, Mangan JA, Monahan IM, Dolganov G, Efron B, Butcher PD, Nathan C, et al. 2003. Transcriptional adaptation of Mycobacterium tuberculosis within macrophages: Insights into the phagosomal environment. J Exp Med 198: 693-704.

Schwegmann A, Brombacher F. 2008. Host-directed drug targeting of factors hijacked by pathogens. Sci Signal 1: re8.

Schwenk A, Macallan DC. 2000. Tuberculosis, malnutrition and wasting. Curr Opin Clin Nutr Metab Care 3: 285291.

Shi S, Ehrt S. 2006. Dihydrolipoamide acyltransferase is critical for Mycobacterium tuberculosis pathogenesis. Infect Immun 74: 56-63.

Shi C, Geders TW, Park SW, Wilson DJ, Boshoff HI, Abayomi O, Barry CE 3rd, Schnappinger D, Finzel BC, Aldrich CC. 2011. Mechanism-based inactivation by aromatization of the transaminase BioA involved in biotin biosynthesis in Mycobaterium tuberculosis. J Am Chem Soc 133: 18194-18201.
Mycobacterium tuberculosis Metabolism

Shimono N, Morici L, Casali N, Cantrell S, Sidders B, Ehrt S, Riley LW. 2003. Hypervirulent mutant of Mycobacterium tuberculosis resulting from disruption of the mcel operon. Proc Natl Acad Sci 100: 15918-15923.

Shin JH, Yang JY, Jeon BY, Yoon YJ, Cho SN, Kang YH, Ryu do H, Hwang GS. 2011. ${ }^{1} \mathrm{H}$ NMR-based metabolomic profiling in mice infected with Mycobacterium tuberculosis. J Proteome Res 10: 2238-2247.

Shitikov EA, Bespyatykh JA, Ischenko DS, Alexeev DG, Karpova IY, Kostryukova ES, Isaeva YD, Nosova EY, Mokrousov IV, Vyazovaya AA, et al. 2014. Unusual large-scale chromosomal rearrangements in Mycobacterium tuberculosis Beijing B0/W148 cluster isolates. PLoS ONE 9: e84971.

Singh V, Jamwal S, Jain R, Verma P, Gokhale R, Rao KV. 2012. Mycobacterium tuberculosis-driven targeted recalibration of macrophage lipid homeostasis promotes the foamy phenotype. Cell Host Microbe 12: 669-681.

Slayden RA, Jackson M, Zucker J, Ramirez MV, Dawson CC, Crew R, Sampson NS, Thomas ST, Jamshidi N, Sisk P, et al. 2013. Updating and curating metabolic pathways of TB. Tuberculosis (Edinb) 93: 47-59.

Smith DA, Parish T, Stoker NG, Bancroft GJ. 2001. Characterization of auxotrophic mutants of Mycobacterium tuberculosis and their potential as vaccine candidates. Infect Immun 69: 1142-1150.

Smith PM, Howitt MR, Panikov N, Michaud M, Gallini CA, Bohlooly YM, Glickman JN, Garrett WS. 2013. The microbial metabolites, short-chain fatty acids, regulate colonic $\mathrm{T}_{\mathrm{reg}}$ cell homeostasis. Science 341: 569-573.

Somashekar BS, Amin AG, Tripathi P, MacKinnon N, Rithner CD, Shanley CA, Basaraba R, Henao-Tamayo M Kato-Maeda M, Ramamoorthy A, et al. 2012. Metabolomic signatures in guinea pigs infected with epidemicassociated W-Beijing strains of Mycobacterium tuberculosis. J Proteome Res 11: 4873-4884.

Stanley SA, Barczak AK, Silvis MR, Luo SS, Sogi K, Vokes M, Bray MA, Carpenter AE, Moore CB, Siddiqi N, et al. 2014. Identification of host-targeted small molecules that restrict intracellular Mycobacterium tuberculosis growth. PLoS Pathog 10: e1003946.

Stinear TP, Seemann T, Harrison PF, Jenkin GA, Davies JK, Johnson PD, Abdellah Z, Arrowsmith C, Chillingworth T, Churcher C, et al. 2008. Insights from the complete genome sequence of Mycobacterium marinum on the evolution of Mycobacterium tuberculosis. Genome Res 18: 729-741.

Strelko CL, Lu W, Dufort FJ, Seyfried TN, Chiles TC, Rabinowitz JD, Roberts MF. 2011. Itaconic acid is a mammalian metabolite induced during macrophage activation. $J$ Am Chem Soc 133: 16386-16389.

Supply P, Marceau M, Mangenot S, Roche D, Rouanet C, Khanna V, Majlessi L, Criscuolo A, Tap J, Pawlik A, et al. 2013. Genomic analysis of smooth tubercle bacilli provides insights into ancestry and pathoadaptation of $M y$ cobacterium tuberculosis. Nat Genet 45: 172-179.

Tannahill GM, Curtis AM, Adamik J, Palsson-McDermott EM, McGettrick AF, Goel G, Frezza C, Bernard NJ, Kelly B, Foley NH, et al. 2013. Succinate is an inflammatory signal that induces IL-1 $\beta$ through HIF- $1 \alpha$. Nature 496: $238-242$. 
D.F. Warner

Thomas ST, VanderVen BC, Sherman DR, Russell DG, Sampson NS. 2011. Pathway profiling in Mycobacterium tuberculosis: Elucidation of cholesterol-derived catabolite and enzymes that catalyze its metabolism. J Biol Chem 286: $43668-43678$.

Tian J, Bryk R, Itoh M, Suematsu M, Nathan C. 2005a. Variant tricarboxylic acid cycle in Mycobacterium tuberculosis: Identification of $\alpha$-ketoglutarate decarboxylase. Proc Natl Acad Sci 102: 10670-10675.

Tian J, Bryk R, Shi S, Erdjument-Bromage H, Tempst P, Nathan C. 2005b. Mycobacterium tuberculosis appears to lack $\alpha$-ketoglutarate dehydrogenase and encodes pyruvate dehydrogenase in widely separated genes. $\mathrm{Mol} \mathrm{Mi-}$ crobiol 57: 859-868.

Timm J, Post FA, Bekker LG, Walther GB, Wainwright HC, Manganelli R, Chan WT, Tsenova L, Gold B, Smith I, et al. 2003. Differential expression of iron-, carbon-, and oxygen-responsive mycobacterial genes in the lungs of chronically infected mice and tuberculosis patients. Proc Natl Acad Sci 100: 14321-14326.

Tsolaki AG, Hirsh AE, DeRiemer K, Enciso JA, Wong MZ, Hannan M, Goguet de la Salmoniere YO, Aman K, KatoMaeda M, Small PM. 2004. Functional and evolutionary genomics of Mycobacterium tuberculosis: Insights from genomic deletions in 100 strains. Proc Natl Acad Sci 101: 4865-4870.

Tullius MV, Harmston CA, Owens CP, Chim N, Morse RP, McMath LM, Iniguez A, Kimmey JM, Sawaya MR, Whitelegge JP, et al. 2011. Discovery and characterization of a unique mycobacterial heme acquisition system. Proc Natl Acad Sci 108: 5051-5056.

* Uhía I, Williams KJ, Shahrezaei V, Robertson BD. 2014. Mycobacterial growth. Cold Spring Harb Perspect Med doi: $10.1101 /$ cshperspect.a021097.

Vandal OH, Pierini LM, Schnappinger D, Nathan CF, Ehrt S. 2008. A membrane protein preserves intrabacterial $\mathrm{pH}$ in intraphagosomal Mycobacterium tuberculosis. Nat Med 14: $849-854$.

Ventura M, Rieck B, Boldrin F, Degiacomi G, Bellinzoni M, Barilone N, Alzaidi F, Alzari PM, Manganelli R, O'Hare HM. 2013. GarA is an essential regulator of metabolism in Mycobacterium tuberculosis. Mol Microbiol 90: $356-$ 366.

Venugopal A, Bryk R, Shi S, Rhee K, Rath P, Schnappinger D, Ehrt S, Nathan C. 2011. Virulence of Mycobacterium tuberculosis depends on lipoamide dehydrogenase, a member of three multienzyme complexes. Cell Host Microbe 9: $21-31$.

Via LE, Lin PL, Ray SM, Carrillo J, Allen SS, Eum SY, Taylor K, Klein E, Manjunatha U, Gonzales J, et al. 2008. Tuberculous granulomas are hypoxic in guinea pigs, rabbits, and nonhuman primates. Infect Immun 76: 2333-2340.

Via LE, Weiner DM, Schimel D, Lin PL, Dayao E, Tankersley SL, Cai Y, Coleman MT, Tomko J, Paripati P, et al. 2013. Differential virulence and disease progression following Mycobacterium tuberculosis complex infection of the common marmoset (Callithrix jacchus). Infect Immun 81: 2909-2919.

Wagner D, Maser J, Lai B, Cai Z, Barry CE 3rd, Honer Zu Bentrup K, Russell DG, Bermudez LE. 2005. Elemental analysis of Mycobacterium avium-, Mycobacterium tuberculosis-, and Mycobacterium smegmatis-containing phag- osomes indicates pathogen-induced microenvironments within the host cell's endosomal system. J Immunol 174: 1491-1500.

Wagner T, Bellinzoni M, Wehenkel A, O’Hare HM, Alzari PM. 2011. Functional plasticity and allosteric regulation of $\alpha$-ketoglutarate decarboxylase in central mycobacterial metabolism. Chem Biol 18: 1011-1020.

Warner DF, Mizrahi V. 2008. Physiology of Mycobacterium tuberculosis. In Tuberculosis handbook, Vol. 1 (ed. Rubin EJ, Kaufmann SHE), pp. 53-59. Wiley-VCH, Weinheim, Germany.

Warner DF, Mizrahi V. 2012. Approaches to target identification and validation for tuberculosis drug discovery: A UCT perspective. S Afr Med J 102: 457-460.

Warner DF, Savvi S, Mizrahi V, Dawes SS. 2007. A riboswitch regulates expression of the coenzyme $\mathrm{B}_{12}$-independent methionine synthase in Mycobacterium tuberculosis: Implications for differential methionine synthase function in strains H37Rv and CDC1551. J Bacteriol 189: 36553659.

Watanabe S, Zimmermann M, Goodwin MB, Sauer U, Barry CE 3rd, Boshoff HI. 2011. Fumarate reductase activity maintains an energized membrane in anaerobic Mycobacterium tuberculosis. PLoS Pathog 7: e1002287.

Wei JR, Krishnamoorthy V, Murphy K, Kim JH, Schnappinger D, Alber T, Sassetti CM, Rhee KY, Rubin EJ 2011. Depletion of antibiotic targets has widely varying effects on growth. Proc Natl Acad Sci 108: 4176-4181.

Weiner B, Gomez J, Victor TC, Warren RM, Sloutsky A, Plikaytis BB, Posey JE, van Helden PD, Gey van Pittius NC, Koehrsen M, et al. 2012a. Independent large scale duplications in multiple $M$. tuberculosis lineages overlapping the same genomic region. PLoS ONE 7: e26038.

Weiner J 3rd, Parida SK, Maertzdorf J, Black GF, Repsilber D, Telaar A, Mohney RP, Arndt-Sullivan C, Ganoza CA, Fae KC, et al. 2012b. Biomarkers of inflammation, immunosuppression and stress with active disease are revealed by metabolomic profiling of tuberculosis patients. PLoS ONE 7: e40221.

Wheeler PR, Ratledge C. 1994. Metabolism of Mycobacterium tuberculosis. In Tuberculosis: Pathogenesis, protection, and control (ed. Bloom BR), pp. 353-385. American Society for Microbiology, Washington, DC.

Williams M, Mizrahi V, Kana BD. 2014. Molybdenum cofactor: A key component of Mycobacterium tuberculosis pathogenesis? Crit Rev Microbiol 40: 18-29.

Wolfe LM, Veeraraghavan U, Idicula-Thomas S, Schurer S, Wennerberg K, Reynolds R, Besra GS, Dobos KM. 2013. A chemical proteomics approach to profiling the ATPbinding proteome of Mycobacterium tuberculosis. Mol Cell Proteomics 12: 1644-1660.

Woolhiser L, Tamayo MH, Wang B, Gruppo V, Belisle JT, Lenaerts AJ, Basaraba RJ, Orme IM. 2007. In vivo adaptation of the Wayne model of latent tuberculosis. Infect Immun 75: 2621-2625.

Zhang YJ, Ioerger TR, Huttenhower C, Long JE, Sassetti CM, Sacchettini JC, Rubin EJ. 2012. Global assessment of genomic regions required for growth in Mycobacterium tuberculosis. PLoS Pathog 8: e1002946.

Zhang H, Li D, Zhao L, Fleming J, Lin N, Wang T, Liu Z, Li C, Galwey N, Deng J, et al. 2013a. Genome 
sequencing of 161 Mycobacterium tuberculosis isolates from China identifies genes and intergenic regions associated with drug resistance. Nat Genet 45: 12551260.

Zhang YJ, Reddy MC, Ioerger TR, Rothchild AC, Dartois V, Schuster BM, Trauner A, Wallis D, Galaviz S, Huttenhower C, et al. 2013b. Tryptophan biosynthesis protects mycobacteria from CD4 T-cell-mediated killing. Cell 155: 1296-1308.
Zheng J, Rubin EJ, Bifani P, Mathys V, Lim V, Au M, Jang J, Nam J, Dick T, Walker JR, et al. 2013. para-Aminosalicylic acid is a prodrug targeting dihydrofolate reductase in Mycobacterium tuberculosis. J Biol Chem 288: $23447-$ 23456.

Zhou A, Ni J, Xu Z, Wang Y, Lu S, Sha W, Karakousis PC, Yao YF. 2013. Application of ${ }^{1} \mathrm{H}$ NMR spectroscopy-based metabolomics to sera of tuberculosis patients. J Proteome Res 12: 4642-4649. 


\title{
$\&_{\mathrm{CSH}}^{\infty} \&$ Cold Spring Harbor

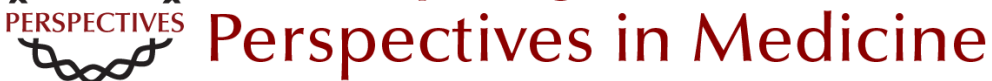

\section{Mycobacterium tuberculosis Metabolism}

\author{
Digby F. Warner
}

Cold Spring Harb Perspect Med 2015; doi: 10.1101/cshperspect.a021121 originally published online December 11, 2014

\section{Subject Collection Tuberculosis}

Transmission and Institutional Infection Control of Tuberculosis Edward A. Nardell

Innate and Adaptive Cellular Immune Responses

to Mycobacterium tuberculosis Infection Katrin D. Mayer-Barber and Daniel L. Barber

Tuberculosis Comorbidity with Communicable and Noncommunicable Diseases

Matthew Bates, Ben J. Marais and Alimuddin Zumla

Host-Directed Therapies for Tuberculosis David M. Tobin

Immunity and Immunopathology in the Tuberculous Granuloma Antonio J. Pagán and Lalita Ramakrishnan

Tuberculosis Drug Development: History and Evolution of the Mechanism-Based Paradigm? Sumit Chakraborty and Kyu Y. Rhee

Genetic Approaches to Facilitate Antibacterial Drug Development Dirk Schnappinger

The Tuberculosis Drug Discovery and Development Pipeline and Emerging Drug Targets Khisimuzi Mdluli, Takushi Kaneko and Anna Upton
Clinical Aspects of Adult Tuberculosis Robert Loddenkemper, Marc Lipman and Alimuddin Zumla

Advances in Diagnostic Assays for Tuberculosis Stephen D. Lawn

Diagnosis and Management of Latent

Tuberculosis Infection

Laura Muñoz, Helen R. Stagg and Ibrahim Abubakar

Mycobacterial Growth Iria Uhía, Kerstin J. Williams, Vahid Shahrezaei, et al.

Multidrug-Resistant Tuberculosis and Extensively

Drug-Resistant Tuberculosis Kwonjune J. Seung, Salmaan Keshavjee and Michael L. Rich

The Mycobacterial Cell Wall--Peptidoglycan and

Arabinogalactan Luke J. Alderwick, James Harrison, Georgina S. Lloyd, et al.

Tuberculosis and HIV Coinfection Judith Bruchfeld, Margarida Correia-Neves and Gunilla Källenius

Imaging in Tuberculosis Jamshed B. Bomanji, Narainder Gupta, Parveen Gulati, et al.

For additional articles in this collection, see http://perspectivesinmedicine.cshlp.org/cgi/collection/ 